Article

\title{
Characterisation of Hemp Fibres Reinforced Composites Using Thermoplastic Polymers as Matrices
}

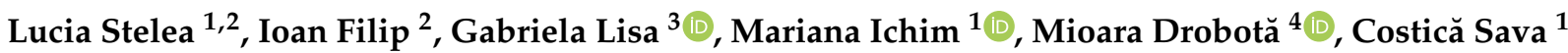 \\ and Augustin Mureșan 1,*
}

1 Faculty of Industrial Design and Business Management, Gheorghe Asachi Technical University of Iasi, D. Mangeron Street, No. 29, 700050 Iasi, Romania; luci.stelea@taparo.ro (L.S.); mariana.ichim@academic.tuiasi.ro (M.I.); costica_sava@yahoo.com (C.S.)

2 Taparo Company S.A.,198 Borcut Street, 435600 Targu Lapus, Romania; ioan.filip@taparo.ro

3 Faculty of Chemical Engineering and Environmental Protection, Gheorghe Asachi Technical University of Iasi, 700050 Iasi, Romania; gapreot@ch.tuiasi.ro

4 Petru Poni Institute of Macromolecular Chemistry, 41A Grigore Ghica Voda Street, 700487 Iasi, Romania; miamiara@icmpp.ro

* Correspondence: aug_muresan@yahoo.com

Citation: Stelea, L.; Filip, I.; Lisa, G.; Ichim, M.; Drobotă, M.; Sava, C.; Mureșan, A. Characterisation of Hemp Fibres Reinforced Composites Using Thermoplastic Polymers as Matrices. Polymers 2022, 14, 481. https://doi.org/10.3390/ polym14030481

Academic Editor: Yung-Sheng Yen

Received: 9 December 2021

Accepted: 20 January 2022

Published: 25 January 2022

Publisher's Note: MDPI stays neutral with regard to jurisdictional claims in published maps and institutional affiliations.

Copyright: (C) 2022 by the authors. Licensee MDPI, Basel, Switzerland. This article is an open access article distributed under the terms and conditions of the Creative Commons Attribution (CC BY) license (https:// creativecommons.org/licenses/by/ $4.0 /)$.

\begin{abstract}
Hemp fibres used as a reinforcing agent and three polymeric matrices (polypropylene, bicomponent, recycled polyester) were used to obtain composite materials by needle punching and heat pressing. The influence of the hemp/matrix ratio and the nature of the matrix on the properties of the composites were analysed. The obtained composites were characterised by physicalmechanical indices, thermal analysis (thermogravimetry (TG), differential thermogravimetry (DTG) and Differential Scanning Calorimetry (DSC)), Fourier Transform Infrared Spectroscopy (FTIR-ATR) analysis, Scanning Electron Microscopy (SEM) and Chromatic measurements. The mechanical properties of composites are influenced by both the hemp/matrix ratio and the nature of the matrix. The thermal stability of composites decreased as the amount of hemp increased (for the same mass losses, the decomposition temperature decreased significantly for composites containing a quantity of hemp greater than 50\%). Regarding the nature of the matrix, for the same mass loss, the highest decomposition temperature was presented by the composites containing recycled polyester as matrix, and the lowest one was presented by composites containing polypropylene fibres as matrix. The FTIR and SEM analyses highlight the changes that occurred in the structure of the composite, changes determined both by the amount of hemp in the composite and by the nature of the matrix.
\end{abstract}

Keywords: composites; hemp reinforcement; polymer matrix; thermal stability; FTIR; SEM; colour strength

\section{Introduction}

In recent decades, due to their wide range of properties, composite materials have successfully replaced traditional materials such as metals, wood and plastics in many industrial fields: aerospace, automotive, energy, construction, marine, transportation, infrastructure, electronics and electrotechnics, agriculture, food, chemical, furniture, packaging, sports and recreation [1-7]. The rapid growth of the composite material market is closely related with performance limitations of traditional materials, such as the availability and the price. Composite materials combine the qualities of two or more materials with different properties in a product that has superior characteristics over the individual constituents. One constituent is called matrix, and embeds the other constituent, called the reinforcement. The reinforcement takes over the load and gives the composite material strength and rigidity, and the matrix binds the reinforcements together and transfers the load to and between the reinforcements. Polymer composites reinforced with natural lignocellulosic fibres are intensively studied as replacements in common applications for composites reinforced 
with synthetic fibres (glass, carbon, aramid) because of the environmental and economic disadvantages that the latter have [8-10]. Synthetic fibres are costly and non-biodegradable, their production is energy consuming, and the composites obtained from them are not easily recycled. In comparison with synthetic fibres, natural fibres are cheap, biodegradable, renewable, recyclable, nontoxic, and easily available. They have low density, good mechanical properties and do not degrade the processing equipment [11-14].

At present, composite materials obtained from polymeric matrices reinforced with natural cellulose fibres are particularly important due to their ecological nature, biodegradability, low price and high mechanical properties. These materials must meet several basic conditions: they must be completely combustible and biodegradable. To compensate for some deficiencies of natural fibres, such as their lower thermal stability, increased water absorption capacity and less incompatibility with the polymer matrix, researchers are constantly discovering new methods for obtaining composite materials with new properties. In the future, these composite materials are expected to play an increasingly important role [15].

Among natural fibres, hemp is one of the strongest and stiffest, fibreand therefore it has an enormous potential to be used as a reinforcement in composite materials [16].

In addition, industrial hemp (Cannabis sativa) seems to be one of the most profitable crops. One hectare of hemp is the equivalent of four hectares of forest, when we talk about the pulp used to make paper. The vegetation period of hemp is about 100 days, which does not compare to the time required to plant and obtain cellulose from the trees of a forest.

Hemp fibre is a plant that during growth produces an amount of oxygen equal to the amount of $\mathrm{CO}_{2}$ that is released when burning the same amount of hemp.

In Europe, in recent years, hemp production has increased considerably from 94,120 tons in 2015 to 152,820 tons in 2019, an increase of $62.4 \%$ [17,18]. Due to its positive impact on the environment and high yield, hemp is a valuable crop for producers. Taking into account that the farmers from European Union countries may benefit from support for hemp cultivation, one can say that hemp production has shown an upward trend, which makes it easy to use and available for industrial applications. Environmental concerns and hemp's unique characteristics have boosted research concerning the use of hemp fibres as reinforcement in composites. Hemp fibres can be used successfully to obtain biocomposites $[19,20]$.

It can be stated that hemp fibres can be used in obtaining composite materials for multiple uses. By using various treatments, the of a matrix-hemp fibre interface can be improved. By properly choosing polymeric matrices, composite materials can be obtained that can be totally or partially biodegradable, and sometimes with a level of low moisture absorption [21,22].

Studies regarding the properties and applications of composite materials obtained using hemp fibres as reinforcing agents and various matrices, such as polyethylene [23-25], cement [26,27], polyurethane [28], polylactic acid [29] and polypropylene [30-36], are presented in the literature. Different authors have highlighted compression molding, extrusion, and injection molding as technologies suitable for processing the composites [37-42].

The processing of hemp fibres is influenced by the processing temperature, and the upper limit is conditioned by the temperature at which the degradation of cellulose and its companions begins [43-46].

The aim of this paper was to obtain and characterise composite materials consisting of hemp fibres and three different polymer fibres used as matrices: polypropylene (PP), bicomponent fibres (BI) and recycled polyester fibres (PES), which have melting temperatures lower than the degradation temperature of hemp. The composite materials were obtained using various mixing ratios of hemp fibres with the three polymer matrices. The resulting materials were characterised by their mechanical properties, thermogravimetric analysis (TG/DTG), Differential Scanning Calorimetry (DSC), Fourier Transform Infrared Spectroscopy (FTIR), Scanning Electron Microscopy (SEM) and chromatic measurements. 


\section{Materials and Methods}

\subsection{Materials}

Hemp fibres with a reinforcing role and three chemical fibres with a matrix role were used for the study. The virgin PP used in this work was purchased from EurocomfilsrlTg. Lapus, Romania, being produced by the Beauileu International Group, Kruisem, Belgium. It has the following characteristics: melting flow index $(\mathrm{MFI})=7.5 \mathrm{~g} / 10 \mathrm{~min}\left(230^{\circ} \mathrm{C} / 2.16 \mathrm{~kg}\right)$; density $=900 \mathrm{~kg} / \mathrm{m}^{3}$; melting temperature $=160{ }^{\circ} \mathrm{C}$. The bicomponent fibre (produced by the company Far Eastern Textile LTD, Taiwan) is of type C/C (cover/core) with a polypropylene sheath and polyester (poly(ethylene terephthalate) core purchased by SC Taparo SA, Tg. Lapus, Romania. The recycled polyester fibres (poly (ethylene terephthalate) were produced by Green Group Fibre Company, Buzau, Romania by recycling polyester bottles. The hemp fibres were purchased from SRL Pianu de Jos Company, Alba County, Romania. The lengths of the fibres in the bales range between 5 and $25 \mathrm{~cm}$. The fibres were cut to 5-6 cm lengths in order to be used.

The main characteristics of the fibres used in composites are presented in Table 1.

Table 1. Characteristics of the fibres used to obtain composites.

\begin{tabular}{ccccc}
\hline Fibres & \multicolumn{5}{c}{ Characteristics } \\
\hline & Title (dtex) & Tenacity (cN/tex) & Elongation (\%) & Fibre Length (mm) \\
\hline Hemp & 102 & 39.5 & 1.8 & $50-250 ; 50 / 60$ \\
\hline Polypropylene & 6.7 & 27 & 100 & 60 \\
\hline Polyester & 19 & 28.5 & 50.80 & $38 / 64$ \\
\hline Bicomponent & 6.7 & 28 & 52 & 51 \\
\hline
\end{tabular}

\subsection{Experimental Variants}

In order to obtain composite materials, hemp fibres $(\mathrm{H})$ as reinforcing agent and three types of thermoplastic polymer fibres as matrix were used: polypropylene (PP), bicomponent fibre (BI) and recycled polyester fibres (PES). Within each variant the percentage composition of the two components was modified from 0 to $100 \%$. The coding and composition of the materials according to the experimental variants are presented in Table 2.

Table 2. Working variants.

\begin{tabular}{|c|c|c|c|c|c|}
\hline Variant & Blend & Variant & Blend & Variant & Blend \\
\hline V 1.1 & $100 \mathrm{H}$ & V 2.1 & $100 \mathrm{H}$ & V 3.1 & $100 \mathrm{H}$ \\
\hline V 1.2 & 75H25PP & V 2.2 & $75 \mathrm{H} 25 \mathrm{BI}$ & V 3.2 & 75H25PES \\
\hline V 1.3 & 50H50PP & V 2.3 & $50 \mathrm{H} 50 \mathrm{BI}$ & V 3.3 & 50H50PES \\
\hline V 1.4 & 25H75PP & V 2.4 & 25H75BI & V 3.4 & 25H75PES \\
\hline V 1.5 & $100 \mathrm{PP}$ & V 2.5 & 100BI & V.3.5 & 100PES \\
\hline
\end{tabular}

\subsection{Composites Processing}

The manufacturing process of composite materials consisted of the following steps:

- Manufacturing of needle-punched nonwoven fabrics;

- Overlapping of nonwoven fabrics. Four samples of each nonwoven fabric variant have been overlaid alternatively in the longitudinal and transversal directions;

- Thermoforming. The overlaid nonwovens were placed in the mould of the thermoforming machine and then heated and pressed between the plates until the polymer matrix melted. The material was cooled in the rectangular mould (temperature $-190-240{ }^{\circ} \mathrm{C}$, pressure - 735.46 MPa, pressing time-15 min and cooling time-15 min). 


\subsection{Characterisation}

\subsubsection{Mechanical Properties}

In accordance with the specifications of EN 326-1 standard, type 2 samples ( $250 \mathrm{~mm}$ length, $25 \mathrm{~mm}$ width) were used for tensile testing. The distance between clamps was $150 \mathrm{~mm}$ and the testing speed was $2 \mathrm{~mm} / \mathrm{min}$ as specified in SR EN ISO 527-4:2000 standard. The tensile test was performed on a ZWICK tensile tester (Ulm, Germany) at $23^{\circ} \mathrm{C}$ according to ISO 527-4 standard. Five repetitions were done for each sample.

\subsubsection{Thermogravimetric Analysis (TG/DTG)}

The thermogravimetric measurements were performed using a Mettler Toledo TGA/SDTA 851 balance (Columbus, OH, US), allowing the simultaneous recording of the weight losses (TG) and the derivative thermogravimetric curves (DTG). The analysis was carried out under constant nitrogen flow $(20 \mathrm{~mL} / \mathrm{min})$, at a heating rate of $10^{\circ} \mathrm{C} / \mathrm{min}$. The heating scans were performed on $1.9-5.3 \mathrm{mg}$ of sample in the temperature range $25-700{ }^{\circ} \mathrm{C}$.

\subsubsection{Differential Scanning Calorimetry (DSC)}

The melting and crystallisation behaviour of the composites was studied using a Mettler Toledo DSC1 differential scanning calorimeter (Columbus, OH, US). The mass of samples encapsulated in aluminium pans with pierced lids to allow evaporation of the volatile components ranged between 2.2 and $5.4 \mathrm{mg}$. A nitrogen flow rate of $150 \mathrm{~mL} / \mathrm{min}$ was used. The sample was initially scanned from -60 to $200{ }^{\circ} \mathrm{C}$ or -60 to $300{ }^{\circ} \mathrm{C}$ at a heating rate of $10 \mathrm{~K} / \mathrm{min}$ and followed by cooling with the same rate, and then it was rescanned in the same temperature interval. The crystallisation temperature $(\mathrm{Tc})$, the crystallisation enthalpy $\left(\mathrm{H}_{\mathrm{c}}\right)$, the melting temperature $(\mathrm{Tm})$ and the melting enthalpy $\left(\mathrm{H}_{\mathrm{m}}\right)$ were obtained from the heating-cooling-heating cycle of the sample. The crystallinity, $\mathrm{X}_{\mathrm{c}}(\%)$, of the different compounds was obtained by Equation (1).

$$
\mathrm{X}_{\mathrm{c}}(\%)=\left[\frac{\Delta \mathrm{H}_{\mathrm{m}}}{\Delta \mathrm{H}_{\mathrm{m}}^{0} \cdot(1-\mathrm{w})}\right] \cdot 100
$$

where in $\Delta \mathrm{H}_{\mathrm{m}}^{0}$ corresponds to the theoretical melting enthalpy of the fully crystalline polypropylene, whose value according to the literature's data is $207 \mathrm{~J} \cdot \mathrm{g}^{-1}$, and $\mathrm{w}$ is the mass fraction of the filler [47].

\subsubsection{Fourier Transform Infrared Spectroscopy}

For the spectroscopic studies, a Bruker FTIR Vertex 70 spectrometer equipped with a diamond ATR (attenuated total reflection) device (Golden Gate; Bruker, Billerica, MA, USA) and ATR-FTIR (attenuated total reflection Fourier transform infrared) was used. The ATRFTIR spectra were measured in the spectral range of $800-4000 \mathrm{~cm}^{-1}$, by the accumulation of 64 scans.

\subsubsection{Scanning Electron Microscopy}

The scanning electron microscopy studies were performed on samples fixed on aluminium supports. The surface morphology of the uncoated samples was examined using an SEM-type Quanta 200 (FEI) (Hillsboro, OR, USA), operating at $20 \mathrm{kV}$ with secondary electrons in the low vacuum mode (large-field detector (LFD)), the magnification being indicated on the micrographs.

\subsubsection{Chromatic Measurements}

Samples of composite materials were subjected to colour measurements performed on the entire spectrum of the visible range. The sample were evaluated for colour strength in terms of Kubelca-Munk equation [48]

$$
\frac{\mathrm{K}}{\mathrm{S}}=\frac{(1-\mathrm{R})^{2}}{2 \mathrm{R}}
$$


wherein " $R$ " is the reflectance at sample complete opacity;

" $\mathrm{K}$ " is the absorption coefficient;

" $\mathrm{S}$ " is the scattering coefficient.

A DATACOLOR SF-300 spectrophotometer (Lawrence Township, NJ, USA) was used for this purpose. The processing of the experimental data was performed with the help of some specialised software, Micromach ${ }^{\mathrm{R}} 2000$.

\section{Results and Discussions}

\subsection{Mechanical Properties}

The mechanical properties of the fibres used as reinforcing agents, of the polymeric fibres used as matrices, and of the composite materials obtained from them are shown in Figures $1-3$. The $100 \%$ hemp sample, which is a nonwoven material, has a much lower tensile strength $(0.76 \mathrm{MPa})$ than composite materials. The tensile strengths of composite materials containing hemp fibre as a reinforcer increased as the content of the polymer matrix increased. The highest values were obtained for the composites that contain a quantity of hemp ranging between 30 and $50 \%(w / w)$, after which there was a slight decreasing tendency of the tensile strength. Regarding the nature of the matrix, the highest values of tensile strength were obtained for composite materials with polyester matrix $(26.2 \mathrm{MPa})$, followed by composite materials with bicomponent fibre (23.77 MPa) and then by composite materials with polypropylene (20.33 MPa).

The elongation at break of the $100 \%$ hemp nonwoven material was approximately $71.5 \%$, and this decreased in the composite materials as the hemp content increased. This decrease can be explained by the increased crystallinity of these composite materials (Table 4). The elongations at break of the $100 \%$ polymer matrices are higher than those of the composite materials. PP has the highest value of elongation at break $(14.1 \%)$, being followed by BI (12.5\%) and afterthen by PES (8.3\%). These values confirm the role of the reinforcing agent used in obtaining the composite materials.
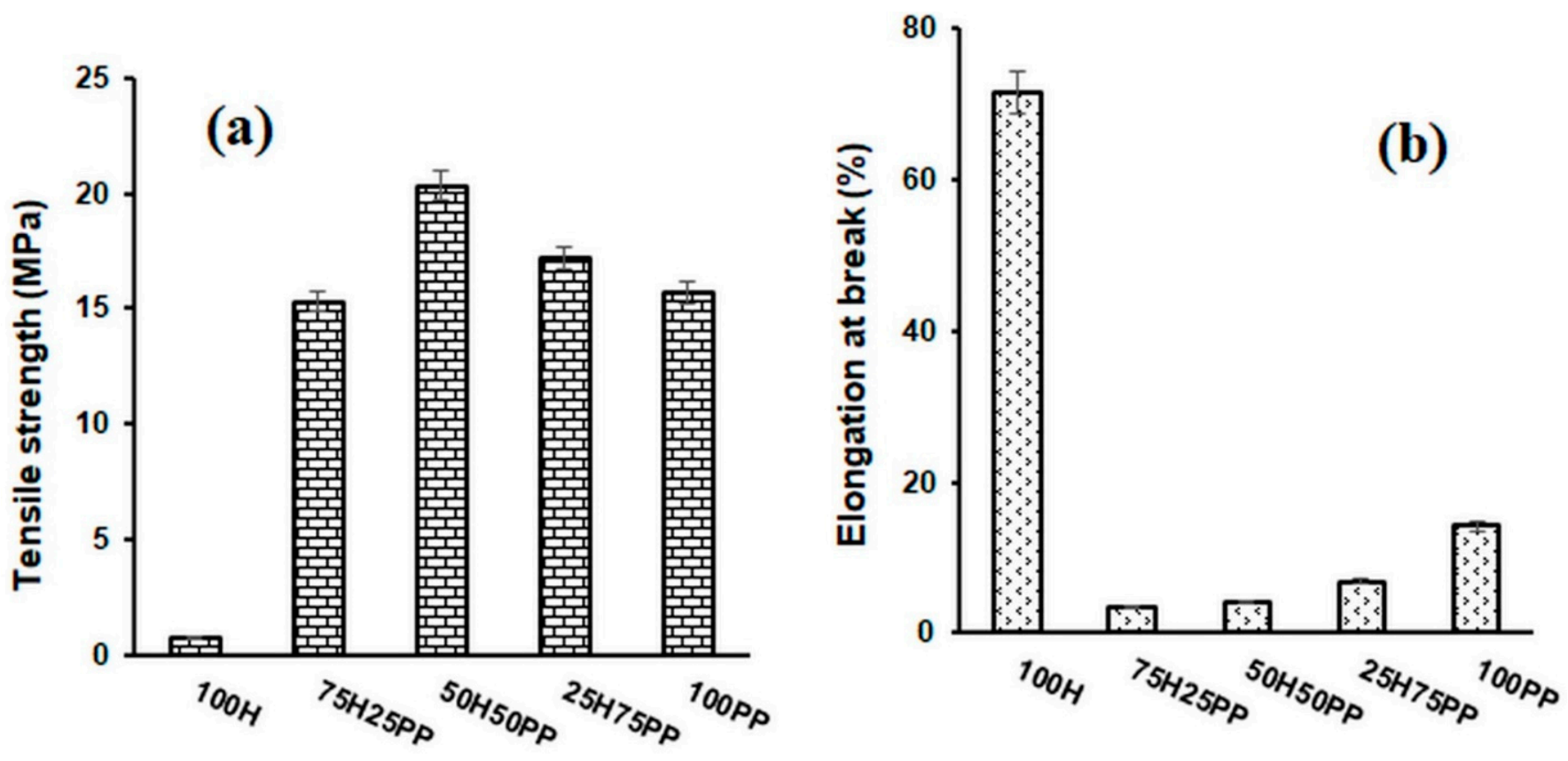

Figure 1. Variation in tensile strength (a) and elongation at break (b) for hemp and polypropylenefibre composites. 

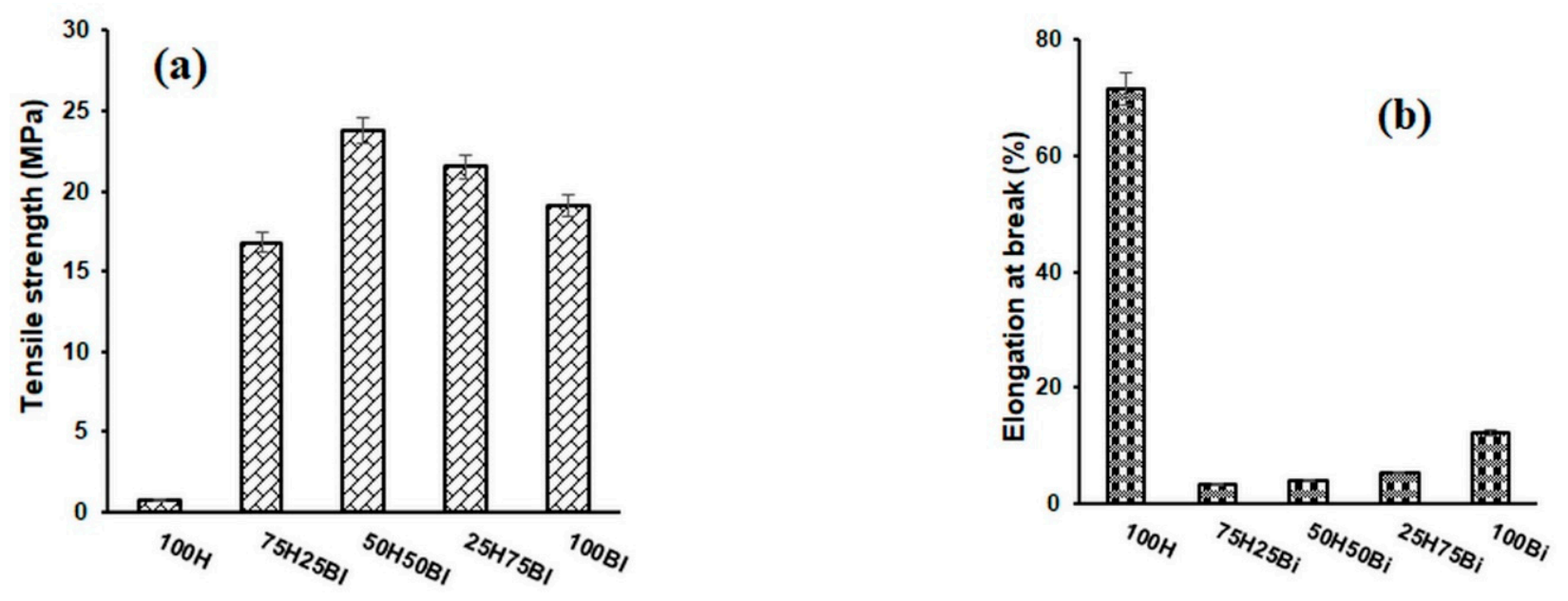

Figure 2. Variation in tensile strength (a) and elongation at break (b) for hemp composites and bicomponent fibres.
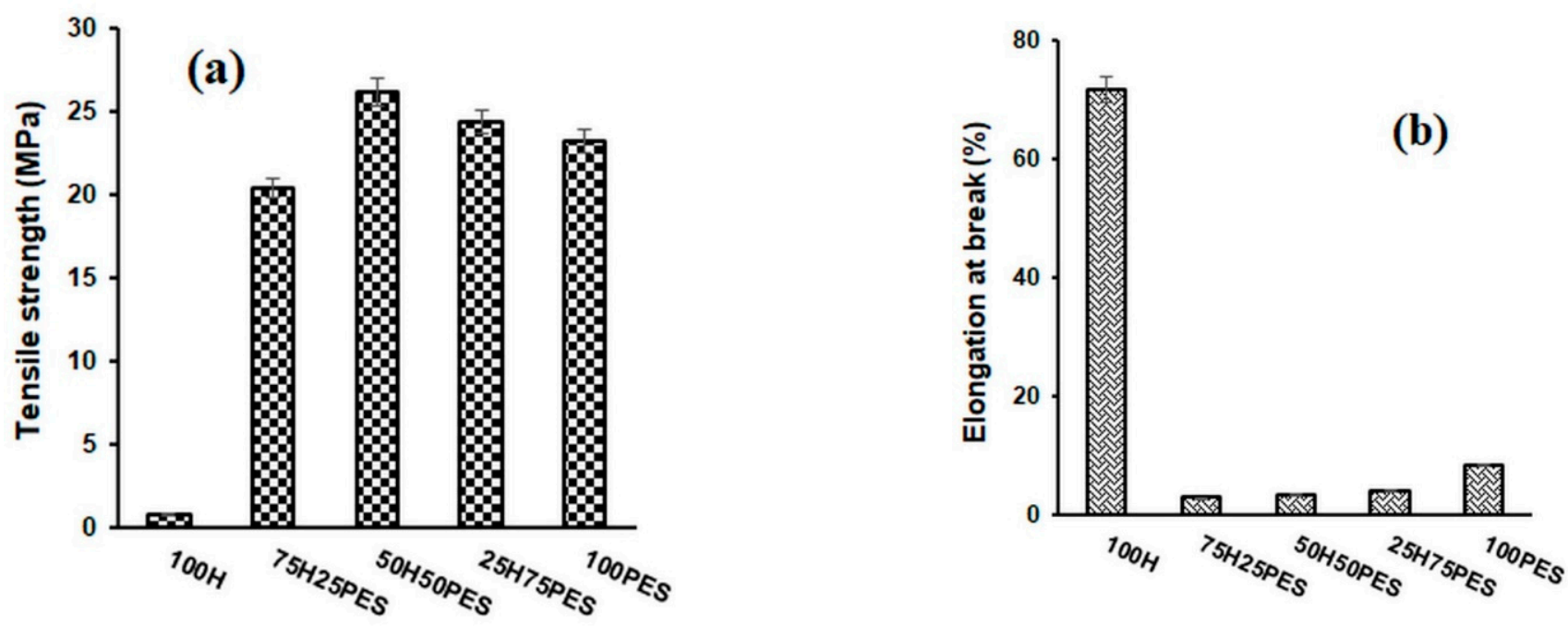

Figure 3. Variation in tensile strength (a) and elongation at break (b) for composite materials of hemp and polyester fibres.

\subsection{TGA and DTG Analysis}

The TGA and DTG thermograms of the hemp fibres used as reinforcers, of the various matrices (formed of polypropylene fibres, polyester fibres and bicomponent fibres) and of the composites obtained from them are presented in Figures 4-6.

Before analysing the thermal behaviour of composite materials, it is important to analyse the thermal behaviour of each component of the composite (Figure 4). When analysing the TG curve of hemp fibre, a mass loss of $7.3 \%$ was observed in the temperature range between 41 and $149^{\circ} \mathrm{C}$, which can be attributed to the loss of moisture from the surface of hemp fibre. In the range $149-303{ }^{\circ} \mathrm{C}$, the mass losses were small $(7.06 \%)$. The highest mass loss of $57.7 \%$ occurred within the temperature range of $303{ }^{\circ} \mathrm{C}$ to $376{ }^{\circ} \mathrm{C}$, and can be attributed to the degradation of cellulose and hemicellulose (the rate of degradation is greatest at $359^{\circ} \mathrm{C}$ ). At temperatures between $376^{\circ} \mathrm{C}$ and $498^{\circ} \mathrm{C}$ and even higher, there was a new mass loss due to lignin degradation [49].

Regarding the DTG curve, the peak at $55^{\circ} \mathrm{C}$ can be attributed to the moisture loss of the hemp fibre, while the sharp peak at $559^{\circ} \mathrm{C}$ is due to the degradation of cellulose and hemicellulose. The peak at $446^{\circ} \mathrm{C}$ can be attributed to lignin degradation. [47].

From the TG diagram of the polyester fibre, it is observed that it did not undergo significant changes up to the temperature of $399^{\circ} \mathrm{C}$. In the temperature range $399-461{ }^{\circ} \mathrm{C}$, 
there was a significant degradation of the fibre (mass loss of $89.33 \%$ ). Degradation continued up to temperature of $650{ }^{\circ} \mathrm{C}$. From the DTG curve, it can be observed that the degradation rate reached its maximum at $434{ }^{\circ} \mathrm{C}$.

By analysing the thermal behaviour of the bicomponent fibre, which is made of PP (cover) and polyester (core), it was observed that up to the temperature of $396{ }^{\circ} \mathrm{C}$, there were no significant changes in terms of weight loss. A significant degradation of the fibre occurred in the range $396-462{ }^{\circ} \mathrm{C}$ (mass loss of $84.97 \%$ ). The degradation continued in the range $462-664^{\circ} \mathrm{C}$, with a mass loss of $14.81 \%$.
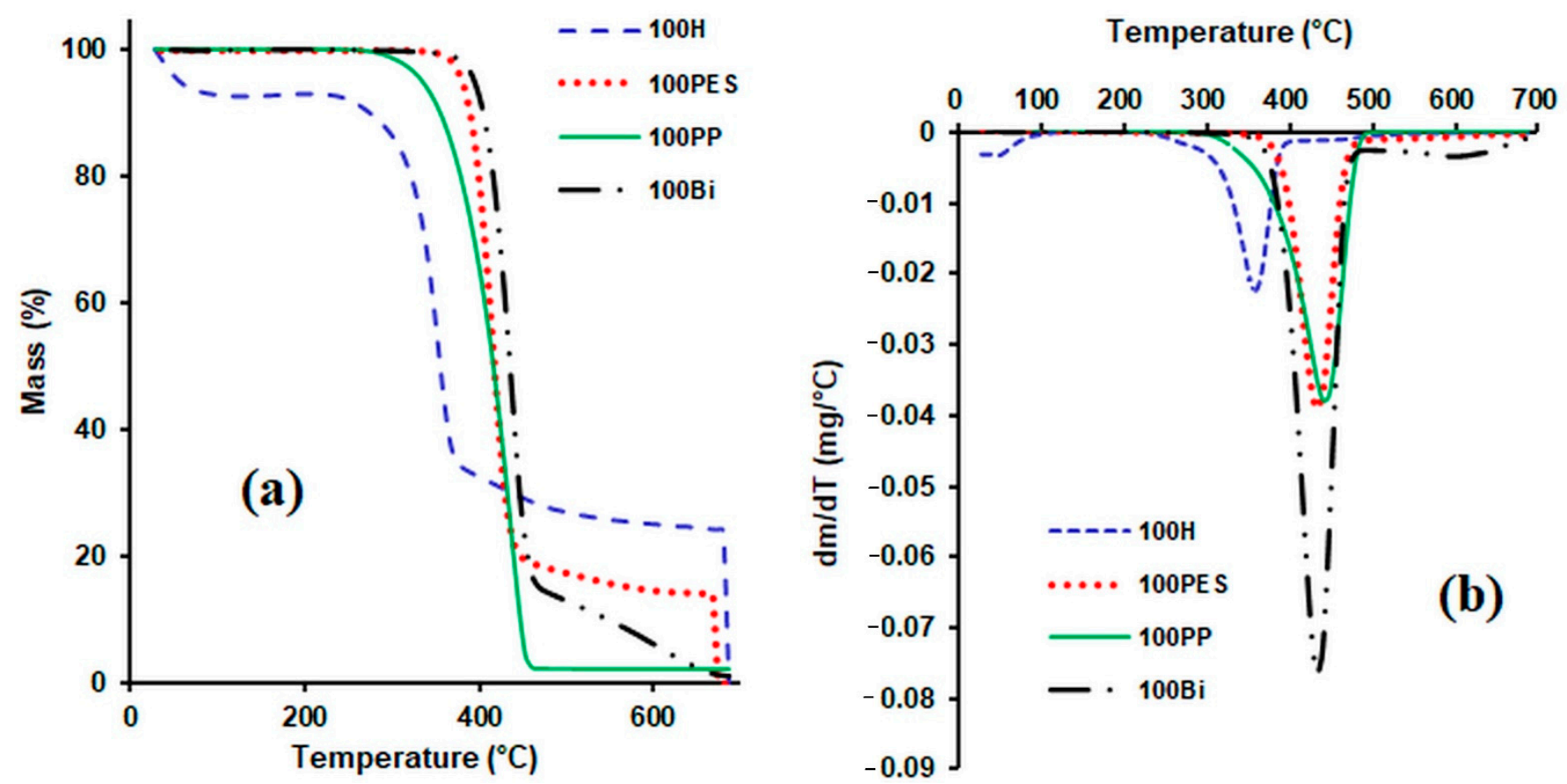

Figure 4. TG curves (a) and DTG curves (b) for hemp fibres and matrix polymer fibres.
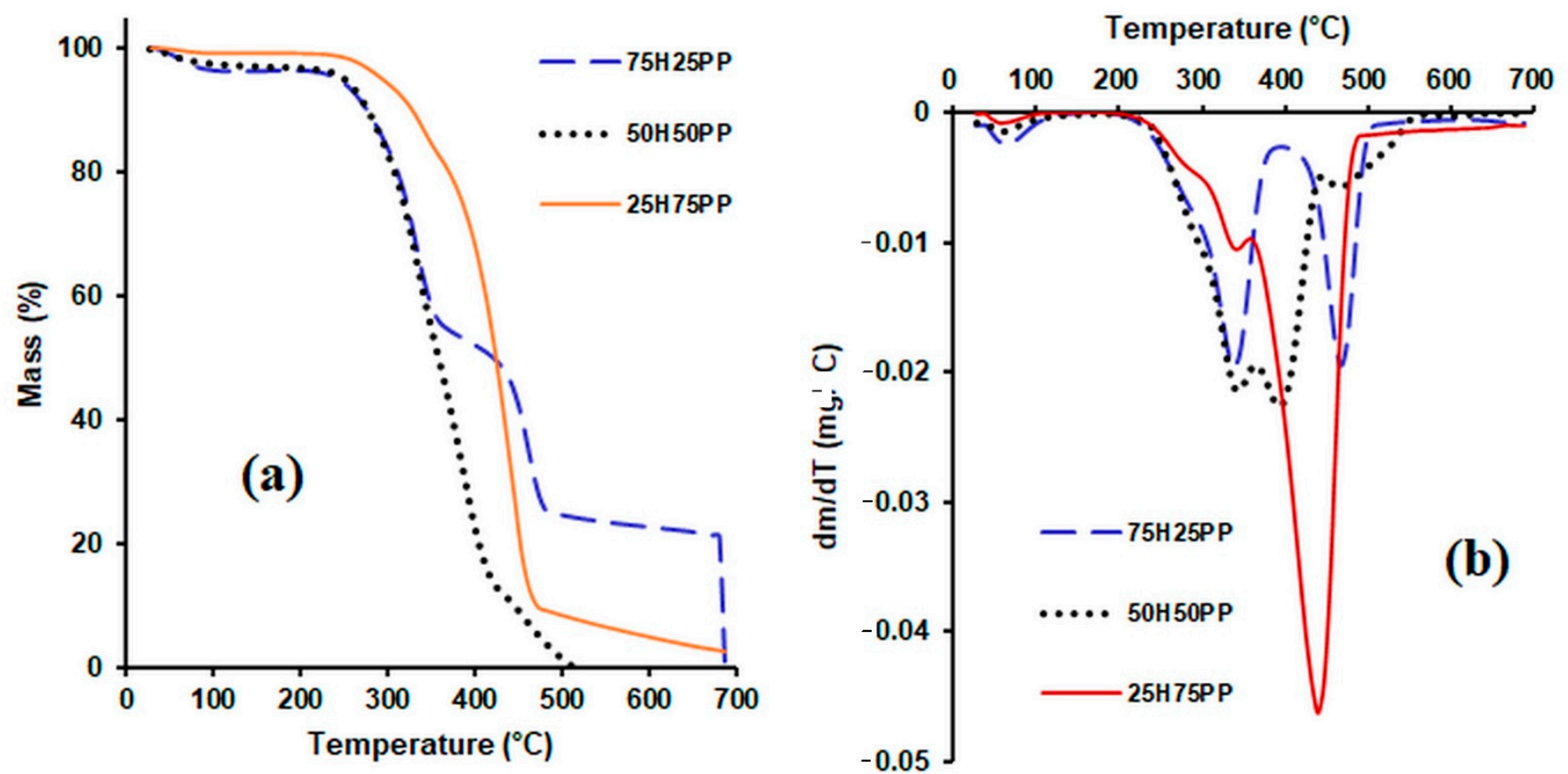

Figure 5. TG curves (a) and DTG curves (b) for composite materials consisting of hemp fibres and polypropylene fibres. 

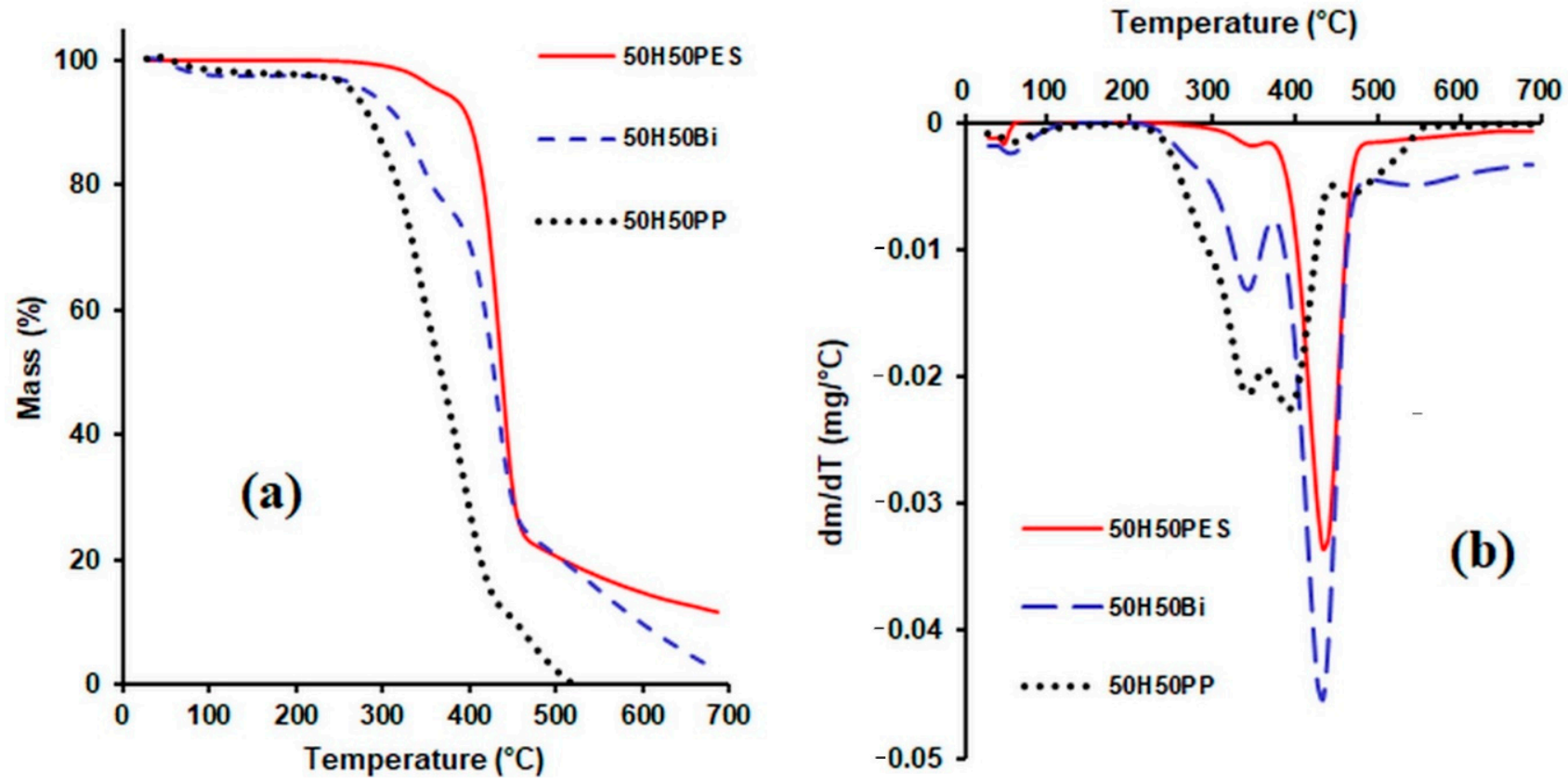

Figure 6. TG curves (a) and DTG curves (b) for composite materials consisting of hemp fibres and various matrices.

The DTG curve of the bicomponent fibre indicates a maximum degradation at the temperature of $436{ }^{\circ} \mathrm{C}$, which can be attributed to the degradation of the polypropylene component, and another one at $601{ }^{\circ} \mathrm{C}$, probably due to the degradation of the polyester component.

From the TG diagram of the polypropylene fibre, it can be observed that a maximum degradation of the fibre occurred in the range $358-469{ }^{\circ} \mathrm{C}$, with a mass loss of $98.14 \%$. From the DTG curve, it can be observed that the maximum degradation of fibre took place at the temperature of $442{ }^{\circ} \mathrm{C}$.

After analysing the TG curves of composite materials containing hemp as the reinforcing agent and polypropylene as the matrix (Figure 5), it can be observed that: in the first stage of degradation (between 25 and $150{ }^{\circ} \mathrm{C}$ ), the mass loss increased with the increase in the hemp content, as would be expected, since the polypropylene matrix has a strong hydrophobic character and does not absorb moisture.

The thermal stability of the analysed composite materials decreased slightly with the increase in the hemp content used as reinforcing agent.

From the TG curves (Figure 6) obtained for the composite materials containing 50\% hemp and 50\% matrix (PP, BI and PES), it can be noticed that the thermal stability of the samples decreased in the following order: composites with polyester fibre matrix $>$ composites with bicomponent fibre matrix $>$ composites with polypropylene matrix. For temperatures higher than $420^{\circ} \mathrm{C}$, the composites with polyester fibre matrix and the composites with bicomponent fibre matrix showed an almost similar behaviour. From the analysis of the DTG curves it can be observed that four peaks appear in the composite material with the PP matrix. The first peak that appears in the range $54-120^{\circ} \mathrm{C}$ corresponds to the loss of moisture, while the peak at $342{ }^{\circ} \mathrm{C}$ corresponds to the degradation of hemp, the peak at $393{ }^{\circ} \mathrm{C}$ can be attributed to the degradation of lignin and PP, and the one at $465{ }^{\circ} \mathrm{C}$ corresponds to the degradation of PP. The temperature range indicated for the use of this composite is $20-120^{\circ} \mathrm{C}$.

For the samples with bicomponent fibre matrix, three peaks occurred. The peak in the range $48-95^{\circ} \mathrm{C}$ can be attributed to the moisture loss of the hemp fibre. The peaks from $344{ }^{\circ} \mathrm{C}$ and $432{ }^{\circ} \mathrm{C}$ can be attributed to the degradation of the hemp fibre and to the polypropylene component of the bicomponent fibre.

Three peaks appear in the DTG diagram of the composite with a polyester matrix. The peak in the range $54-74{ }^{\circ} \mathrm{C}$ can be attributed to the moisture loss from the hemp fibre, the 
one at $344^{\circ} \mathrm{C}$ corresponds to the degradation of the hemp fibre, and the peak at $435^{\circ} \mathrm{C}$ can be attributed to the degradation of the polyester fibre in the composite material.

The most important thermogravimetric characteristics $\left(T_{\text {onset }}\right.$-the starting temperature of the step, $T_{\text {peak }}$ - the temperature corresponding to the maximum value of the mass loss, $\mathrm{T}_{\text {endset }}$ - the ending temperature of each step and $\mathrm{w} \%$-the percentage mass loss corresponding to each interval) are listed in Table 3.

Table 3. Thermogravimetric parameters of the investigated samples.

\begin{tabular}{cccccc}
\hline Sample & Stage & $\mathbf{T}_{\text {onse }}{ }^{\circ} \mathbf{C}$ & $\mathbf{T}_{\text {peak }}{ }^{\circ} \mathbf{C}$ & $\mathbf{T}_{\text {endset }}{ }^{\circ} \mathbf{C}$ & Mass Loss \% \\
\hline \multirow{2}{*}{ 100H } & I & 303 & 359 & 377 & 57.74 \\
100PES & II & 377 & 446 & 499 & 11.31 \\
100BI & I & 399 & 435 & 461 & 89.33 \\
100PP & I & 396 & 436 & 462 & 84.98 \\
& II & 462 & 601 & 664 & 14.81 \\
50H50BI & I & 358 & 437 & 453 & 99.39 \\
& I & 283 & 343 & 357 & 21.43 \\
50 H50PES & II & 357 & 432 & 454 & 50.38 \\
& III & 454 & 546 & 654 & 23.95 \\
$25 H 75 P P$ & I & 328 & 345 & 401 & 9.68 \\
& II & 401 & 435 & 458 & 79.97 \\
& I & 261 & 280 & 321 & 7.46 \\
50H50PP & II & 321 & 340 & 384 & 15.69 \\
& III & 384 & 440 & 463 & 74.10 \\
75H25PP & I & 266 & 342 & 362 & 43.20 \\
& II & 362 & 394 & 424 & 42.61 \\
& III & 424 & 465 & 535 & 14.55 \\
\hline
\end{tabular}

Thermal stability increases as the amount of hemp in the composite decreases. For the same mass losses, the decomposition temperature decreased significantly for the composites that contain hemp in quantities higher than $50 \%$ (Table 4 ).

Table 4. Degradation temperature $\left({ }^{\circ} \mathrm{C}\right)$ and mass loss (\%) of hemp, polymers and composites.

\begin{tabular}{ccccccccccc}
\hline Mass Loss $\%$ & 100H & 75H25PP & 50H50PP & 25H75PP & 100PP & 100BI & 50H50BI & 50H50PES & 100PES \\
\hline 10 & 275 & 276 & 279 & 315 & 386 & 405 & 322 & 403 & 413 \\
\hline 15 & 307 & 296 & 296 & 335 & 396 & 411 & 340 & 411 & 417 \\
\hline 25 & 331 & 321 & 320 & 373 & 411 & 420 & 385 & 422 & 424 \\
\hline 50 & 356 & 346 & 360 & 411 & 434 & 436 & 429 & 437 & 438 \\
\hline
\end{tabular}

Regarding the influence of the matrix on the thermal stability of the composite, it can be observed that the composite material with the polyester fibre matrix exhibited the highest thermal stability, being followed by the composite with a bicomponent fibre matrix. For the same mass losses, the decomposition temperatures of the composites decreased in the order of 50H50PES > 50H50BI > 50H50PP.

\subsection{DSC Analysis}

The DSC thermograms indicate the melting and crystallisation temperatures of the analysed samples (Figures 7-9). From the DSC curves (Figure 7a) corresponding to the heating process, it can be observed that the DSC curve of the hemp fibre shows a low endothermic peak around $63{ }^{\circ} \mathrm{C}$, which corresponds to the decrease in moisture in the fibre. The DSC curve of polypropylene fibre presents an endothermic peak at $165{ }^{\circ} \mathrm{C}$, while the DSC thermogram of the bicomponent fibre shows two peaks, the first one at $71^{\circ} \mathrm{C}$ corresponding to the fibre in the mantle structure, and the second one at about $237^{\circ} \mathrm{C}$ corresponding to the fibre core. In the case of the polyester fibre, the initial melting 
temperature is $235{ }^{\circ} \mathrm{C}$, with a maximum of $239{ }^{\circ} \mathrm{C}$ and a final temperature of $243{ }^{\circ} \mathrm{C}$. The DSC curves obtained in the cooling process (Figure $7 \mathrm{~b}$ ) indicate for hemp fibres an exothermic heat flow that is almost constant in the analysed temperature range. For the other fibres subjected to the cooling process, the crystallisation process takes place at $112{ }^{\circ} \mathrm{C}$ for polypropylene, at $166{ }^{\circ} \mathrm{C}$ for the bicomponent fibre and at $201{ }^{\circ} \mathrm{C}$ for the polyester fibre, respectively.
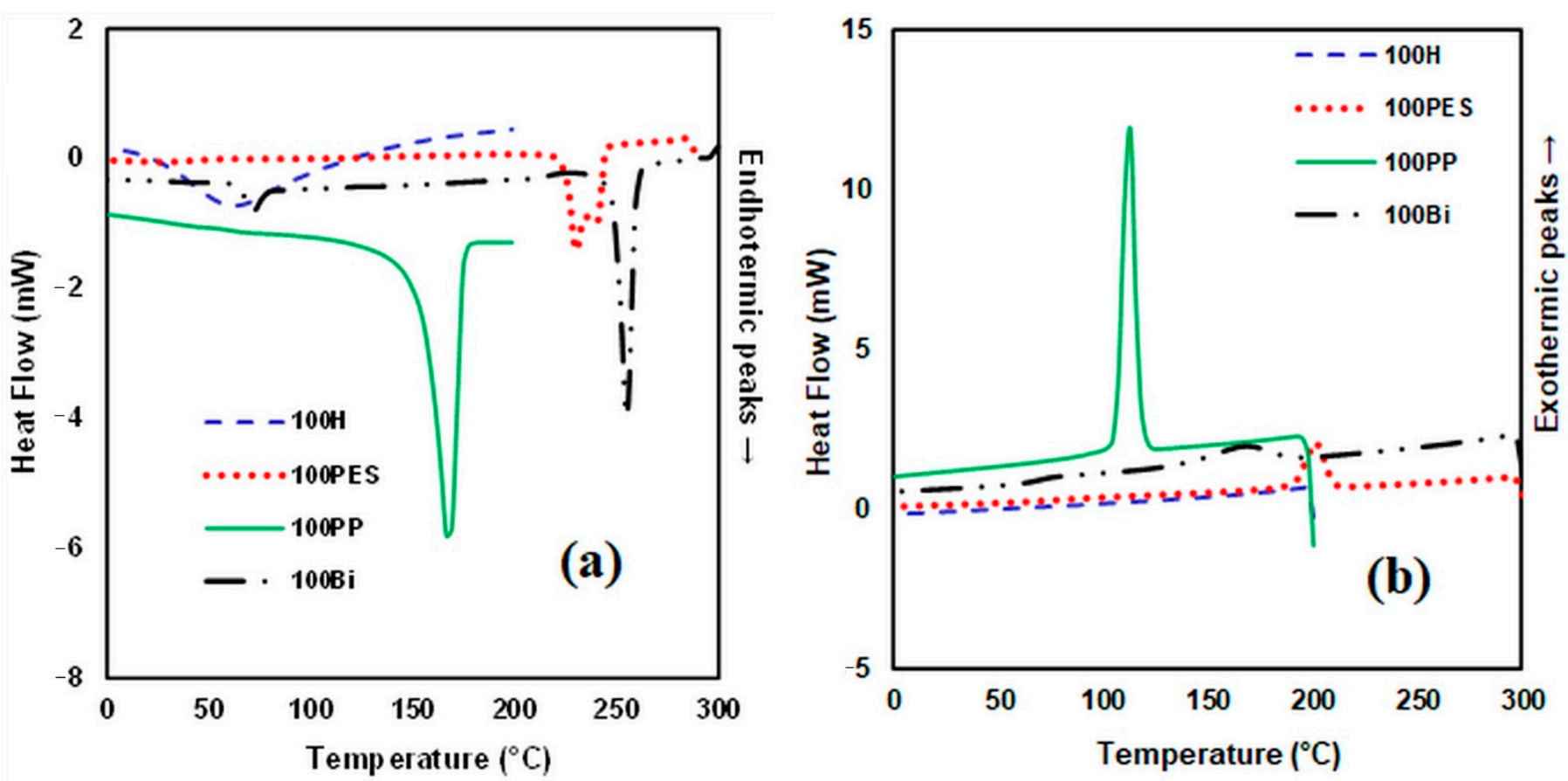

Figure 7. DSC curves heating process (a) and DSC curves cooling process (b) for hemp fibres and various matrices.
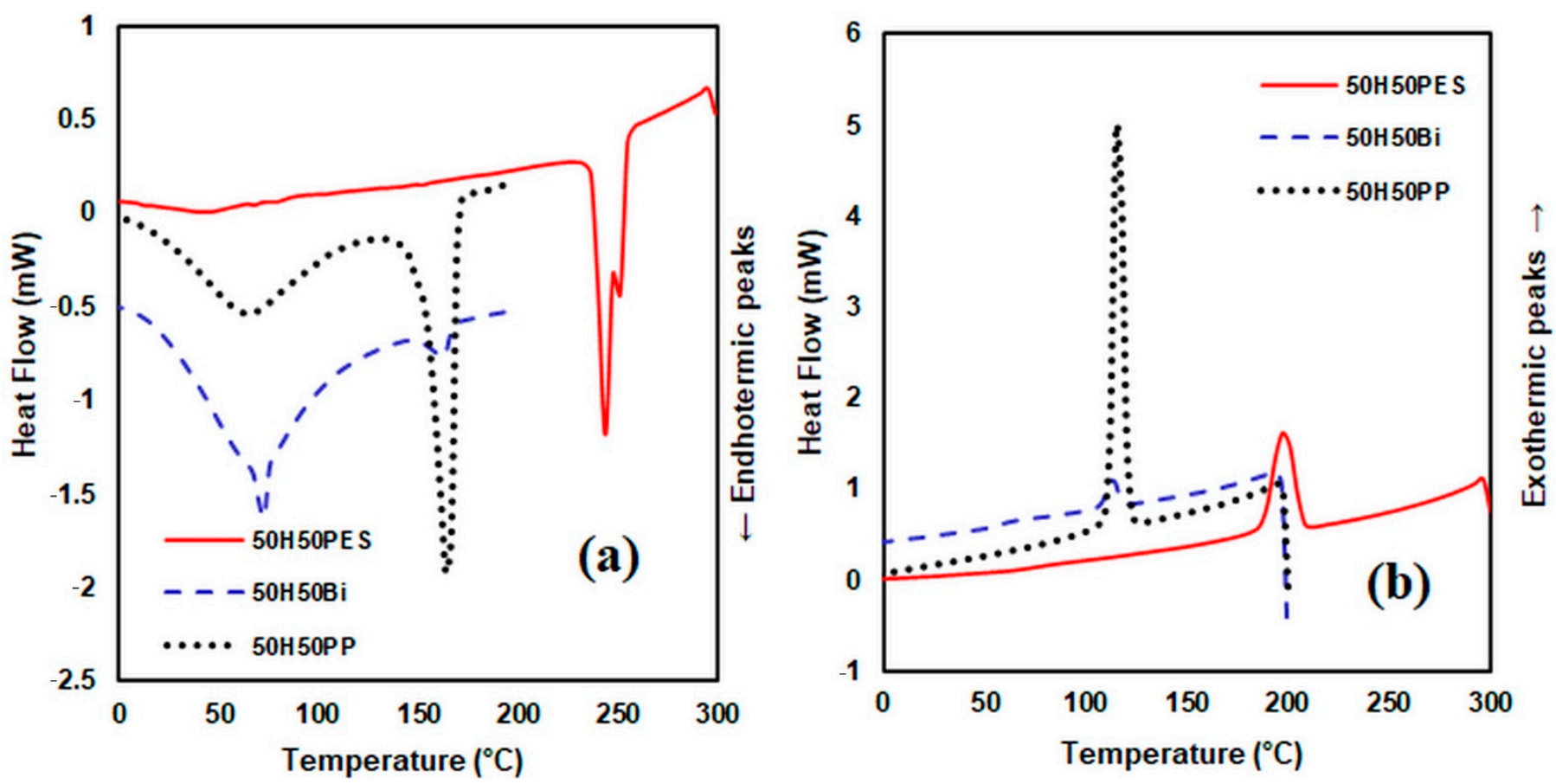

Figure 8. DSC curves heating process (a) and DSC curves cooling process (b) for composite materials consisting of hemp fibres and various matrices. 

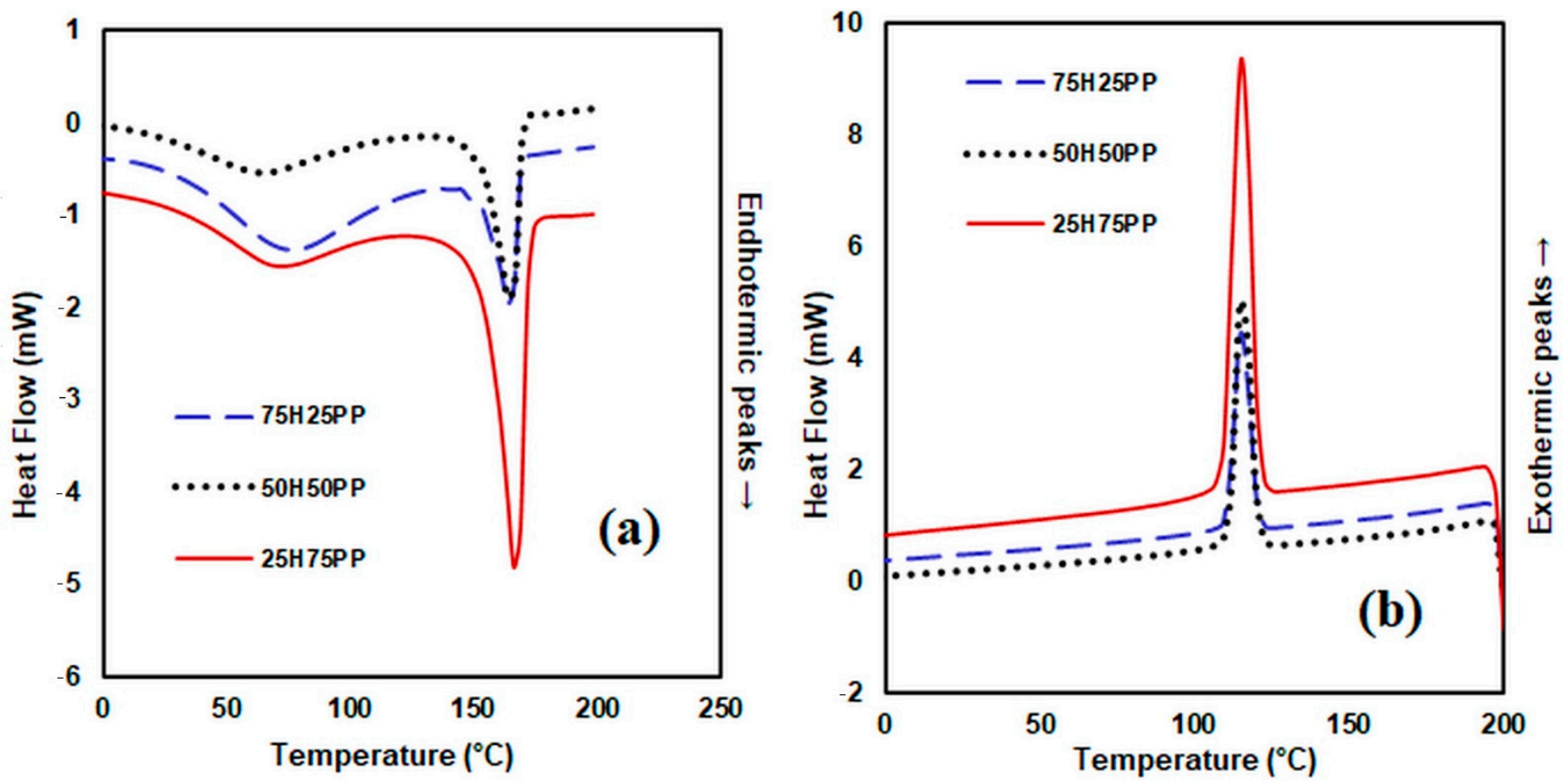

Figure 9. DSC curves heating process (a) and DSC curves cooling process (b) for the composite materials consisting of hemp fibres and polypropylene matrix.

Regarding the nature of the matrix derived from the analysed composites (Figure 8), from the DSC curves, it can be observed that the first peak appears at $62^{\circ} \mathrm{C}$ for the composite $50 \mathrm{H} 50 \mathrm{BI}$, at $72{ }^{\circ} \mathrm{C}$ for the composite $50 \mathrm{H} 50 \mathrm{PP}$ and at $78^{\circ} \mathrm{C}$ for the composite 50H50PES. These peaks are assigned to the endothermic processes that correspond to the evaporation of moisture from the composite material. The second peak occurs at $159^{\circ} \mathrm{C}$ for $50 \mathrm{H} 50 \mathrm{BI}$, at $166^{\circ} \mathrm{C}$ for PP and $248^{\circ} \mathrm{C}$ for polyester fibre, respectively. From the diagrams resulting from the cooling process, the exothermic crystallisation peaks appear at $115^{\circ} \mathrm{C}$ for $50 \mathrm{H} 50 \mathrm{PP}$, at $113^{\circ} \mathrm{C}$ for $50 \mathrm{H} 50 \mathrm{BI}$ and at $197^{\circ} \mathrm{C}$ for 50H50PES, respectively. The composite materials obtained from $25 \mathrm{H} 75 \mathrm{PP}$ and $50 \mathrm{H} 50 \mathrm{PP}$ have a higher melting temperature compared to the melting temperature of $\mathrm{PP}$, while composites obtained from $75 \mathrm{H} 25 \mathrm{PP}$ have a lower melting temperature compared to the melting temperature of PP fibres. This could be explained by an increased interaction between the PP matrix and the reinforcer for composites containing up to $50 \% \mathrm{H}$. These results are also correlated with the results obtained in the case of physical-mechanical indices when the tensile strength increases up to a composition of about $50 \%$ hemp fibres, after which it shows a decreasing tendency.

Regarding the influence of hemp fibre content (Figure 9a) in polypropylene fibre matrix composites, the DSC curves are consistent with the TGA curves. The first endothermic peak appears at $70{ }^{\circ} \mathrm{C}$ for composite $25 \mathrm{H} 75 \mathrm{PP}$, at $72{ }^{\circ} \mathrm{C}$ for composite $50 \mathrm{H} 50 \mathrm{PP}$ and at $75{ }^{\circ} \mathrm{C}$ for composite $75 \mathrm{H} 25 \mathrm{PP}$, respectively.

From the diagram of the cooling process of the composite materials, we can observe an increase with a $2-3{ }^{\circ} \mathrm{C}$ increment in crystallisation temperature (Tc) of the composites compared to pure PP.

The crystallisation temperature of $\mathrm{PP}\left(112.5^{\circ} \mathrm{C}\right.$ read from the cooling curve of Figure $\left.9 \mathrm{~b}\right)$ suggests that PP is a semicrystalline polymer that exhibits a high tendency to crystalise.

The values of the crystallisation temperatures corresponding to the obtained composite materials are close. The difference between the crystallisation temperature of PP and the crystallisation temperatures of the obtained composites is around $3^{\circ} \mathrm{C}$, while the values of their crystallisation temperatures range between 112.5 and $115.55{ }^{\circ} \mathrm{C}$.

This fact confirms that the hemp fibres acted as nucleation agents, and consequently the PP from the composite materials started to crystallise at a temperature higher than 
$112.5^{\circ} \mathrm{C}$, the surface of the hemp fibres constituting crystallisation centers for the polymeric matrix [50].

From Figures 7a and 9a and from Table 5, it can be noticed that during the heating process, a slight decrease in the melting temperature of the composite material, Tm, occurs, compared to the melting temperature of the polymeric matrix. This behaviour was previously reported by other researchers [51,52].

Table 5. DSC data for PP and its composites.

\begin{tabular}{|c|c|c|c|c|c|c|c|c|}
\hline \multirow[b]{2}{*}{ Sample } & \multicolumn{2}{|c|}{ First Heating } & \multicolumn{3}{|c|}{ Cooling } & \multicolumn{3}{|c|}{ Second Heating } \\
\hline & $\mathrm{T}_{\mathrm{m}}\left({ }^{\circ} \mathrm{C}\right)$ & $\Delta H_{m}(J / g) *$ & Tc $\left({ }^{\circ} \mathrm{C}\right)$ & $\Delta \mathbf{H}_{\mathrm{c}}(\mathrm{J} / \mathrm{g})$ & Xc (\%) & $\mathrm{T}_{\mathrm{m}}\left({ }^{\circ} \mathrm{C}\right)$ & $\Delta \mathrm{H}_{\mathrm{m}}(\mathrm{J} / \mathrm{g}) * *$ & Xc $(\%)$ \\
\hline $100 \mathrm{H}$ & & - & - & - & - & & - & \\
\hline $75 \mathrm{H} 25 \mathrm{PP}$ & 161.58 & 32.35 & 115.55 & 39.97 & 77,23 & 161.58 & 35.68 & 68.94 \\
\hline 50H50РP & 163.28 & 41.96 & 115.30 & 54.33 & 52.49 & 162.25 & 46.86 & 45,27 \\
\hline $25 \mathrm{H} 75 \mathrm{PP}$ & 164.26 & 59.19 & 115.20 & 72.33 & 46,58 & 163.20 & 63.42 & 40,85 \\
\hline 100PP & 167.54 & 74.40 & 112.5 & 93.56 & 45,19 & 164.74 & 81.67 & 39.45 \\
\hline
\end{tabular}

This decrease in the melting temperature can be explained by the incompatibility between the PP fibre, which has nepolar groups, and the hemp fibre, a hydrophillic lignocellulosic fibre (between the two types of fibres only weak interactions occurred).

A second scan for the composite samples was also performed (with a second heating). The results obtained from the interpretation of the curves recorded at the second heating, the glass transition temperatures included $\left(T_{g}\right)$, have been inserted in the tables (Tables 5 and 6 ).

Table 6. DSC data for hemp and its composites.

\begin{tabular}{ccccc}
\hline Sample & $\Delta \mathbf{H}_{\mathbf{m}}(\mathbf{J} / \mathbf{g})^{*}$ & $\Delta \mathbf{H}_{\mathbf{c}}(\mathbf{J} / \mathbf{g})$ & $\Delta \mathbf{H}_{\mathbf{m}}(\mathbf{J} / \mathbf{g}) * *$ & $\mathbf{T}_{\mathbf{g}}\left({ }^{*} \mathbf{C}\right){ }^{* * *}$ \\
\hline 50H50BI & 2.26 & 3.40 & 2.34 & 61.91 \\
\hline 100BI & 31.16 & 18.10 & 26.83 & 70.38 \\
\hline 50H50PES & 42.72 & 36.32 & 31.25 & 74.58 \\
\hline 100PES & 50.70 & 39.68 & 33.81 & 77.52 \\
\hline
\end{tabular}

* First heating. ${ }^{* *}$ Second heating. ${ }^{* * *}$ Glass transition temperature (midpoint).

For the composite materials obtained from PP and hemp, we can observe, on the one hand, an increase in the enthalpy of melting $\Delta \mathrm{H}_{\mathrm{m}}$, and on the other hand a decrease in the crystallinity as the hemp fibre content from the composite decreased. Regarding the enthalpy of crystallisation, the higher the degree of crystallinity of the composite material, the higher the amount of heat released $[53,54]$.

Table 5 shows the values obtained for the crystallisation enthalpy $\Delta \mathbf{H}_{\mathbf{c}}$, the melting enthalpy $\Delta \mathbf{H}_{\mathrm{m}}$ and the level of crystallinity $\mathrm{X}_{\mathrm{c}}$, calculated with Equation (1). The value obtained for the melting enthalpy $\Delta \mathrm{H}_{\mathrm{m}}$ of PP is $74.4 \mathrm{~J} \cdot \mathrm{g}^{-1}$, and close values were previously reported by other authors $\left(\Delta \mathrm{Hm} 74\left(\mathrm{~J} \cdot \mathrm{g}^{-1}\right)\right.$ [55]. It can be noticed that the value of crystallinity $X_{c}$ for PP $(45.19 \%)$ is lower compared to the values of the crystallinity level for the composite materials, which vary from $77.23 \%$ to $46.58 \%$. From the curve recorded at the second heating, it is clear that the melting temperature $T_{m}$ of pure PP was $164.74{ }^{\circ} \mathrm{C}$, while the characteristic melting temperatures of the composite materials ranged from $161.58{ }^{\circ} \mathrm{C}$ to $163.20^{\circ} \mathrm{C}$. The values of the crystallinity level Xc corresponding to the heating process ranged between $40.85 \%$ and $68.94 \%$. Both for the cooling process and the heating process, the values of the crystallinity level for the composite materials were higher than the crystallinity level of pure PP used as matrix. These results could be explained by the nucleation effect exerted by the lignocellulosic hemp fibres on the PP matrix, during the manufacturing of the composite materials. The obtained results regarding the influence of 
the matrix type features on the composite materials containing $50 \%$ hemp and $50 \%$ polymer fibre are shown in Table 6.

The values for the melting enthalpy $\Delta \mathrm{Hm}$ are higher for the polyester fibre than for the bicomponent fibre. Additionally, the values of the melting enthalpy $\Delta \mathrm{Hm}$ of the composite materials obtained from these fibres are lower than those obtained for the polymer matrices.

The values of the glass transition temperature for recycled PES previously reported by other researchers range between 60 and $80^{\circ} \mathrm{C}$ [56-59]. The Tg value obtained by us for recycled PES falls within this range.

\subsection{FTIR Analysis}

The FTIR spectra of the hemp and polypropylene, and of the composite materials for the wave numbers range $\left(3600-600 \mathrm{~cm}^{-1}\right)$, are shown in Figure 10a-e.

The broadband in the range $3429-3349 \mathrm{~cm}^{-1}$ is assigned to the stretching vibrations of the $-\mathrm{OH}$ groups belonging to the cellulose and hemicellulose from the hemp fibre [60].

The peaks located within the range $2963-2856 \mathrm{~cm}^{-1}$ in the FTIR spectra of the hemp, the polymeric fibres and the composite materials can be assigned to both types of stretching vibrations (symmetrical and asymmetrical) of the $\mathrm{C}-\mathrm{H}$ bonds $\left(\mathrm{CH}_{2}\right.$ groups) from the hemp and from the polymeric fibres [61].

The absorption band located in the range $1733-1741 \mathrm{~cm}^{-1}$ corresponds to the stretching vibrations of the $\mathrm{C}=\mathrm{O}$ bonds presented in the lignin, pectin and waxes contained by the hemp fibre. The intensity of this absorption band decreased with the decrease in the hemp content in the composite materials wherein polypropylene was used as the matrix. In the case of polyester fibres, of the bicomponent fibres and of the composite materials containing these fibres as matrices, the peaks located at $1713 \mathrm{~cm}^{-1}, 1717 \mathrm{~cm}^{-1}, 1715 \mathrm{~cm}^{-1}$ and $1719 \mathrm{~cm}^{-1}$ are due to stretching vibrations of the group $\mathrm{C}=\mathrm{O}$ from the polyester.

The intensity of the absorption band around $1640 \mathrm{~cm}^{-1}$, attributed to the bending vibrations of $\mathrm{O}-\mathrm{H}$ bonds from the adsorbed water molecules, decreased once the amount of polypropylene from the composites had increased. This is due to the fact that by decreasing the amount of hemp there are fewer "free" hydroxyl groups engaged in the formation of the hydrogen bonds [62].

The peak detected at $1426 \mathrm{~cm}^{-1}$ in the FTIR spectrum of hemp corresponds to the bending vibrations of $\mathrm{C}-\mathrm{H}$ bonds from the $\mathrm{CH}$ and $\mathrm{CH}_{2}$ groups of cellulose, hemicellulose and lignin. The peak recorded at $1457 \mathrm{~cm}^{-1}$ in the FTIR spectrum of PP and in the FTIR spectra of the composites that contain PP corresponds to the bending vibrations of $\mathrm{C}-\mathrm{H}$ bonds from the $\mathrm{CH}_{2}$ and $\mathrm{CH}_{3}$ groups of propylene [63]. The peak located at $1315 \mathrm{~cm}^{-1}$ in the FTIR spectrum of the hemp, attributed to the rocking vibrations of the $\mathrm{C}-\mathrm{H}$ bonds from the $\mathrm{CH}_{2}$ groups of cellulose, was not found in the FTIR spectra of the rigid composites that contain hemp [64]. The peak recorded at $1026 \mathrm{~cm}-1$ in the FTIR spectrum of hemp, attributed to the stretching vibrations of the $\mathrm{C}-\mathrm{O}$ bonds $(\mathrm{C}-\mathrm{O}-\mathrm{C}$ glycosidic linkages from cellulose and hemi-cellulose, $\mathrm{C}-\mathrm{OH}$ phenolic groups from lignin and $\mathrm{C}-\mathrm{O}-\mathrm{C}$ ether linkages from lignin, respectively), decreased greatly in intensity as the amount of hemp in the composites decreased [65]. The decrease in the peak intensity once the $\mathrm{PP} / \mathrm{H}$ ratio had increased may be due to the steric hindrance that occurs as the amount of PP in the composite increases. The band located around $1094 \mathrm{~cm}^{-1}$ in the FTIR spectra of the polyester fibres, bicomponent fibres and hemp containing composites is attributed to the stretching vibrations of the $\mathrm{C}-\mathrm{O}$ bonds from the ester groups of polyester, as well as to the stretching vibration of the $\mathrm{C}-\mathrm{O}$ bonds from the ether groups of cellulose, hemicellulose and lignin. The peak located around $898 \mathrm{~cm}^{-1}$ is characteristic of the glycosidic $\beta$-linkage from the cellulose and hemicellulose. The peak detected around $872 \mathrm{~cm}^{-1}$ is attributed to the stretching vibrations of the $\mathrm{C}-\mathrm{O}$ bond from the polyester. The peak recorded around $840 \mathrm{~cm}^{-1}$ is assigned to the out-of-plane stretching vibrations of the $\mathrm{C}-\mathrm{H}$ bonds from the aromatic rings present in the lignin [65]. The presence of the peaks located at 721, 723 and $725 \mathrm{~cm}^{-1}$ is related to the out-of-plane stretching vibrations of the $\mathrm{C}-\mathrm{H}$ bonds from the aromatic ring [66]. 

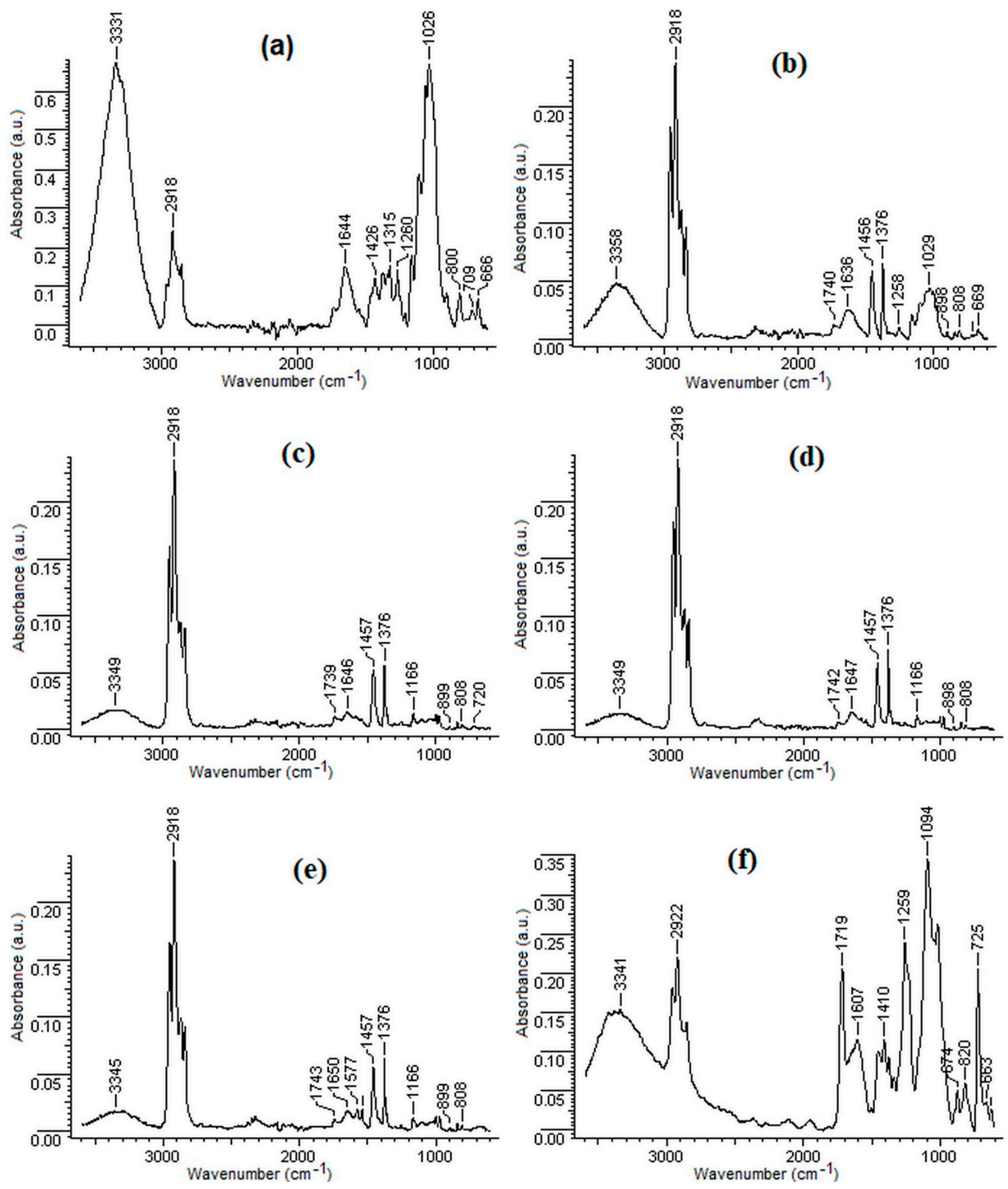

Figure 10. Cont. 

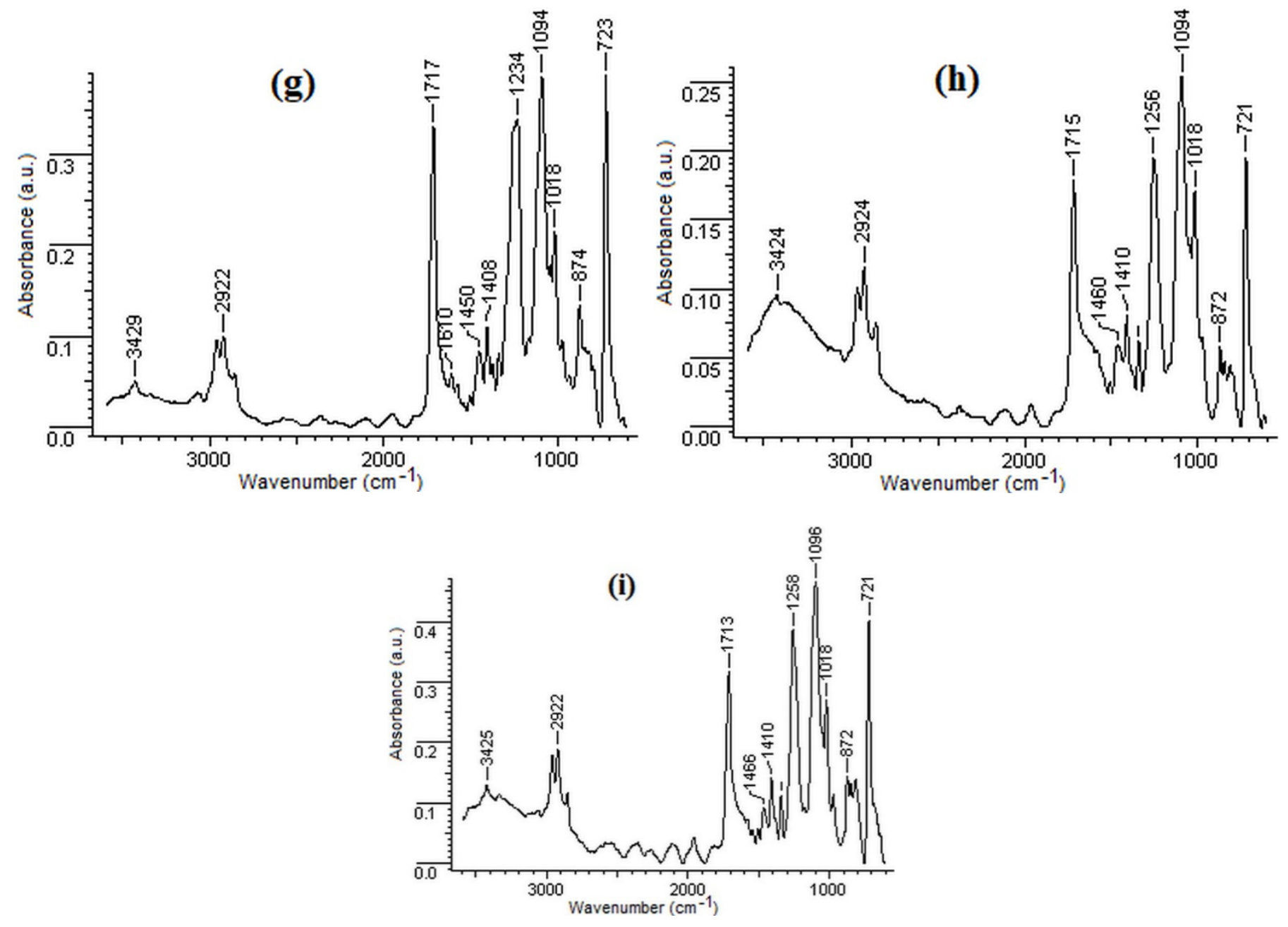

Figure 10. FTIR spectra of (a) 100H; (b) 75H25PP; (c) 50H50PP; (d) 25H75PP; (e) 100PP; (f) 50H50BI; (g) 100BI; (h) 50H50PES and (i) 100PES.

\subsection{SEM Analysis}

The SEM images of the hemp fibres, polymeric fibres and composite materials are presented in Figure 11.

The matrices of PP, PES and BI, the reinforcing agent, and the obtained composite materials were morphologically investigated. The images were recorded at $1000 \times$ and $5000 \times$.

From Figure 11a it can be observed that the size of the hemp fibres is about $50 \mu \mathrm{m}$ and their surface is rough. PP and PE matrices (Figure 11b,c) have a specific compact, homogeneous structure. In the case of the BI matrix, it can be observed that the fibres have a size of approximately $20-30 \mu \mathrm{m}$, and the surface of the fibres is smooth. In order to highlight the influence of the matrix, the morphology of the composite materials with $50 \%$ reinforcing agent (hemp) and 50\% matrix (PP) was analysed (Figure 11f,h,i). From a morphological point of view, good adhesion between components implies a compact structure, in which the reinforcing agent is evenly distributed in the matrix. In Figure 11e-g, the influence of the hemp percentage on the morphology of the H-PP composite can be observed. At a rate of $25-50 \%$ hemp, it can be noticed that the fibres are well integrated into the PP matrix. When the percentage of hemp increases to $75 \%$, some of the fibres are not embedded in the matrix. The results indicated by the SEM images are also confirmed by the physico-mechanical tensile strengths, which increased in the first stage for the composites that contain up to about $50 \%$ hemp, and after that they exhibited a decreasing tendency. 

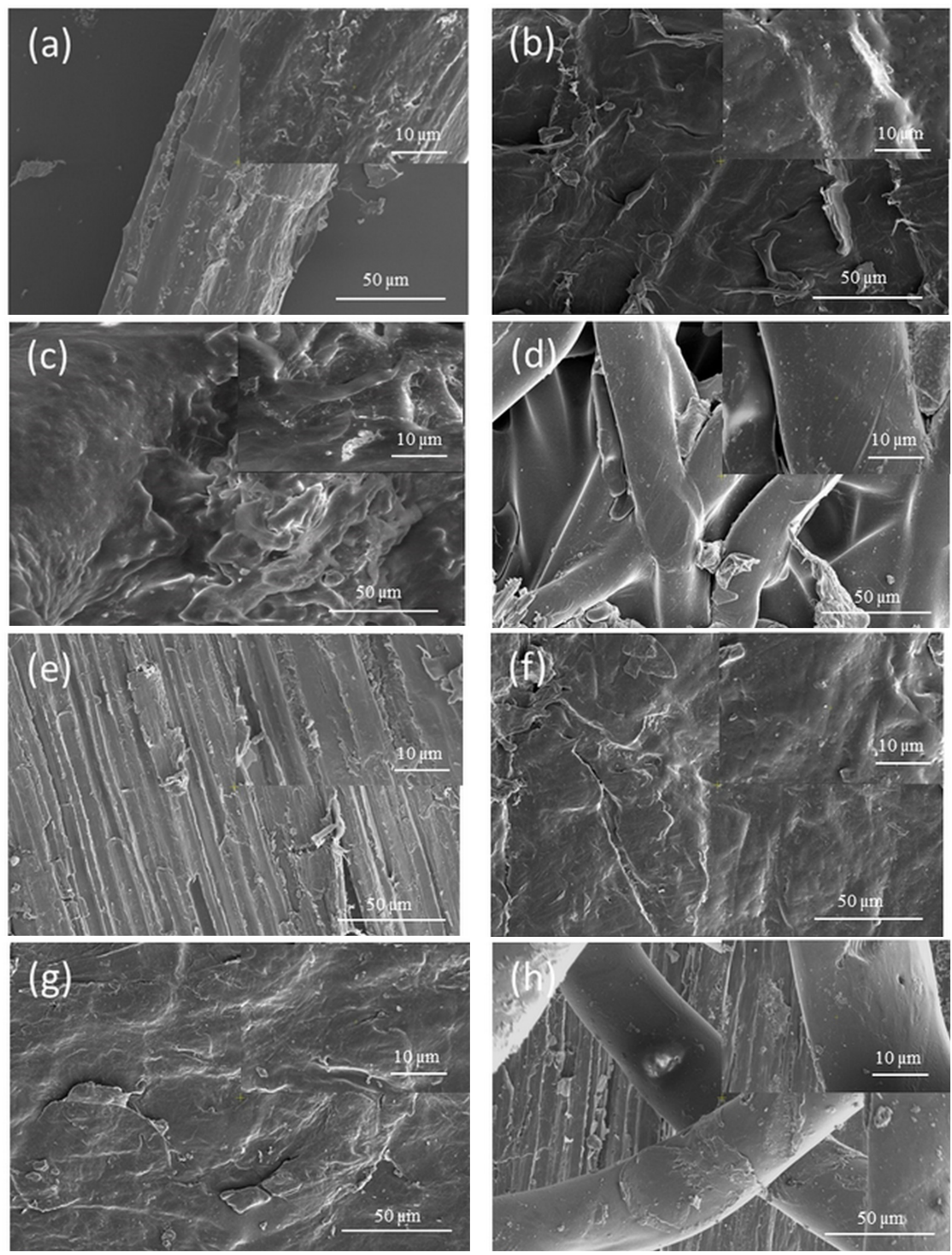

Figure 11. Cont. 


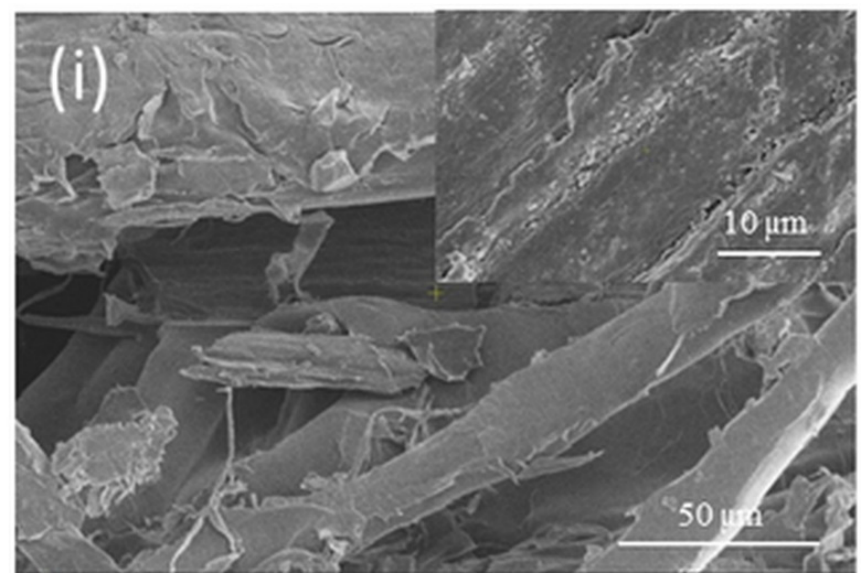

Figure 11. SEM images of (a) hemp fibres, (b) polypropylene, (c) polyester, (d) bicomponent fibres; (e) $75 \mathrm{H} 25 \mathrm{PP}$, (f) 50H50PP, (g) 25H75PP, (h) 50H50PES and (i) 50H50BI.

\subsection{Chromatic Measurements}

Chromatic measurements of composite materials were performed on the entire visible spectrum and were evaluated by colour intensity $(\mathrm{K} / \mathrm{S})$. The obtained results are presented in graphic form in Figure 12. Following the processes of obtaining composite materials, the initial mixture underwent a series of chromatic changes. Under the action of temperature and pressure, the chemical fibre (PP, BI or PES) melted and diffused throughout the mass of hemp fibre.
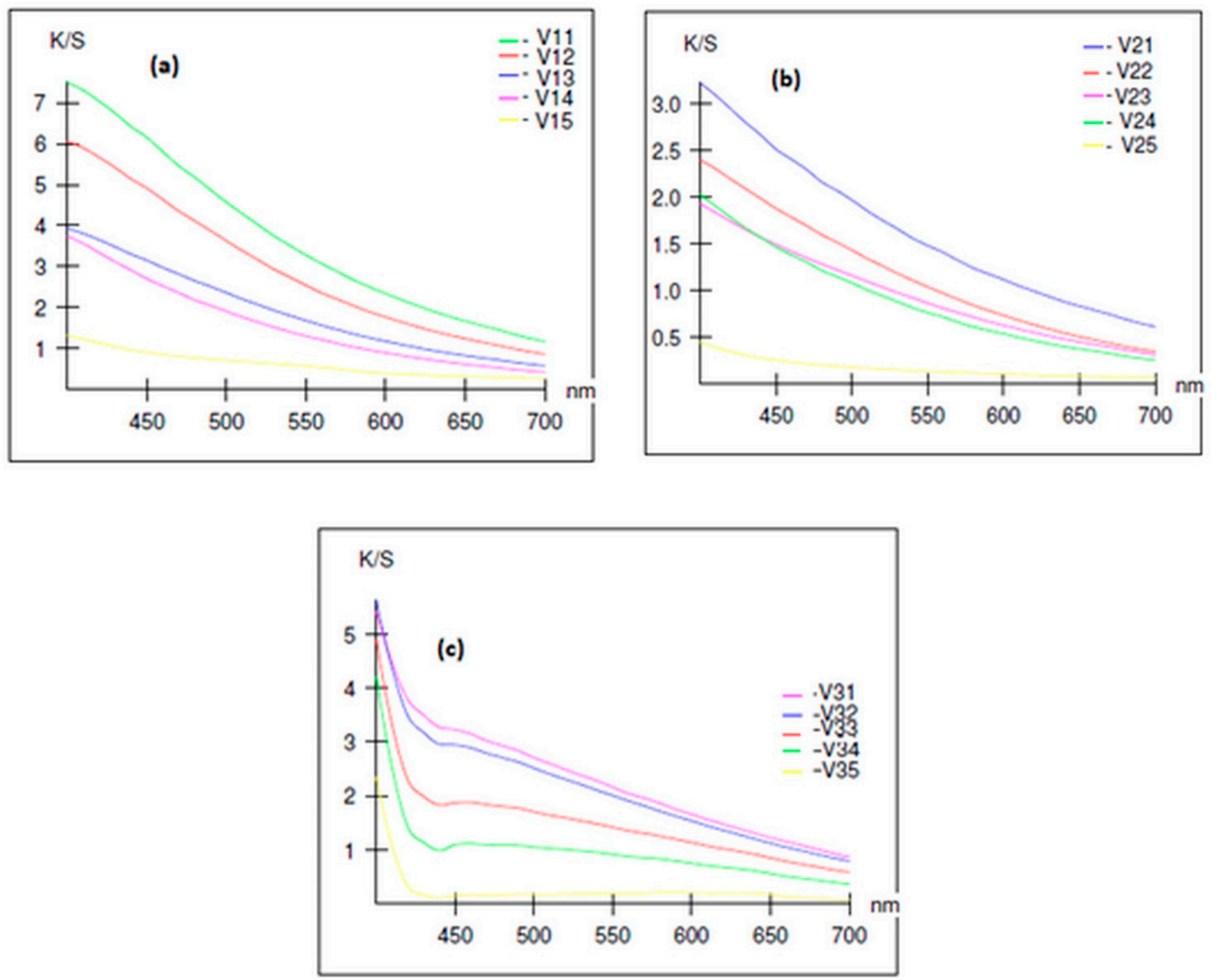

Figure 12. Variation in the colour strength of composite materials obtained from: (a) polypropylene/hemp fibres; (b) bicomponent/hemp fibres; (c) recycled polyester/hemp fibres. 
By cooling, a homogeneous material is obtained whose chromatic characteristics will be influenced by the ratio between the hemp fibre and matrix. In all the analysed variants, the colour intensity of the samples increased with the increase in hemp fibre content, and decreased with the increase in the polymeric fibre content used as matrices.

\section{Conclusions}

In this paper, a comparative study was performed on composite materials obtained by heat pressing from hemp fibres and three polymeric matrices (polypropylene, bicomponents, recycled polyester). The influences of the matrix and of the polypropylene/ hemp ratio were investigated. By analysing the results obtained, the following can be concluded:

- the highest tensile strengths were obtained for composites containing 30\% to 50\% hemp fibres;

- the elongation at break, which is about $71.5 \%$ for the sample consisting of $100 \%$ hemp, falls below $10 \%$ for the composites that contain $25 \%$ polymer matrix;

- thermal stability decreases as the amount of hemp in the composite increases (for the same mass losses, the decomposition temperature decreases significantly for composites containing quantities higher than $50 \%$ hemp), and with regard to the influence of the matrix, for the same mass losses, the decomposition temperature of the composites decreases in the order of 50H50PES > 50H50BI > 50H50PP;

- the SEM images indicate the presence of gaps in the composites that contain a quantity of hemp less than 50\%, which could explain the better adhesiveness between the two components of these composites;

- the colour strength of the composite materials increased with the increase in the amount of hemp fibres, and decreased with the increase in the amount of polymeric fibres used as matrix.

Author Contributions: All authors contributed to the research presented in this work. Their contributions are presented below. Conceptualisation, methodology, investigation, L.S., I.F. and A.M.; formal analysis and data curation, L.S., A.M., C.S., M.I., G.L. and M.D.; writing-original draft preparation A.M., L.S. and M.I.; Funding I.F.; project administration, writing-review and editing, M.I. and A.M. All authors have read and agreed to the published version of the manuscript.

Funding: "This research was funded by the COP Project, No. 267/22.06.2020, ID:121434, MySMIS 121434 "Creating a center of excellence in the field of composite material at SC TAPARO SA", Tg. Lapus, Maramures Country, Romania, funded by the European Union via the European Regional Development Fund and the Romanian Government.

Institutional Review Board Statement: Not applicable.

Informed Consent Statement: Not applicable.

Data Availability Statement: We have uploaded datasets analyzed during study on a shared drive. https:/ / drive.google.com/drive/folders/1Rk-tse9mdti_Cr96kgfqdZGwtK5GqWyP?usp=sharing.

Acknowledgments: This work has been developed within the framework of COP Project No. 267/22.06.2020, MySMIS 121434- “Creating a center of excellence in the field of composite material at SC TAPARO SA", funded by the European Union via the European Regional Development Fund and Romanian Government.

Conflicts of Interest: The authors declare no conflict of interest.

\section{References}

1. Krauklis, A.E.; Karl, C.W.; Gagani, A.I.; Jørgensen, J.K. Composite Material Recycling Technology-State-of-the-Art and Sustainable Development for the 2020s. J. Compos. Sci. 2021, 5, 28. [CrossRef]

2. Yang, Y.; Boom, R.; Irion, B.; van Heerden, D.-J.; Kuiper, P.; de Wit, H. Recycling of composite materials. Chem. Eng. Process. 2012, 51, 53-68. [CrossRef]

3. Shahzad, A. Hemp fibre and its composites-A review. J. Compos. Mater. 2012, 46, 973-986. [CrossRef]

4. Karger-Kocsis, J.; Siengchin, S. Single-Polymer Composites: Concepts, Realization and Outlook: Review. KMUTNB Int. J. Appl. Sci. Technol. 2014, 7, 1-9. [CrossRef] 
5. Saba, N.; Jawaid, M.; Alothman, O.Y. A review on dynamic mechanical properties of natural fibre reinforced polymer composites. Const. Build. Mater. 2016, 106, 149-159. [CrossRef]

6. Meysam, T.; Nuruldiyanah, K.; Zahra, D.; Yee, E.; Ashen, G.; Chandima, G. Conventional and Advanced Composites in Aerospace Industry: Technologies Revisited. AJAE 2018, 5, 9-15.

7. Thiruchitrambalam, M.; Athijayamani, A.; Sathiyamurthy, S.; Syed Abu Thaheer, S.A. A Review on the Natural Fibre-Reinforced Polymer Composites for the Development of Roselle Fibre Reinforced Polyester Composite. J. Nat. Fibers 2010, 7, 307-323. [CrossRef]

8. Andrade, T.; Oliveira, G.; Altoéa, G.R.; Nettoa, P.A.; Muylaert, M.; Oliveira, B.; Neves, M.S. Evaluation of the Diameter Influence on the Tensile Strength of Pineapple Leaf Fibres (PALF) by Weibull Method. Mater. Res. 2015, 18, 185-192.

9. Layth, M.; Ansari, M.N.M.; Pua, G.; Jawaid, M.; Islam, M.S. A Review on Natural Fibre Reinforced Polymer Composite and Its Applications, Hindawi Publishing Corporation. Int. J. Polym. Sci. 2015, 2015, 243947.

10. Chika, E.M.; Chinedum, O.M. Recent Developments in Natural Fibre Composites: A Review. IJAREM $2017,3,28-42$.

11. Kılınç, A.C.; Durmuşkahya, C.; Seydibeyoğlu, M.Ö. Natural fibres. In Fibre Technology for Fibre-Reinforced Composites; Seydibeyoğlu, M.Ö., Mohanty, A.K., Misra, M., Eds.; Composites Science and Engineering; Woodhead Publishing: Cambridge, UK, 2017; pp. 209-235, ISBN 9780081018712.

12. Anuara, N.I.S.; Zakaria, S.; Gan, S.; Chia, C.H.; Wang, C.; Harun, J. Comparison of the morphological and mechanical properties of oil Palm EFB fibres and kenaf fibres in nonwoven reinforced composites. Ind. Crop. Prod. 2019, 127, 55-65. [CrossRef]

13. Gowda, T.G.Y.; Sanjay, M.R.; Subrahmanya, B.K.; Madhu, P.; Senthamaraikannan, P.; Yogesha, B. Polymer matrix-natural fibre composites: An overview. Cogent Eng. 2018, 5, 1446667. [CrossRef]

14. Sullins, T.; Pillay, S.; Komus, A.; Ning, H. Hemp fibre reinforced polypropylene composites: The effects of material treatments. Compos. B Eng. 2017, 114, 15-22. [CrossRef]

15. Khalid, M.Y.; Al Rashid, A.; Arif, Z.U.; Ahmed, W.; Arshad, H.; Zaidi, A.A. Natural fiber reinforced composites: Sustainable the reference num materials for emerging applications. Results Eng. 2021, 11, 100263. [CrossRef]

16. Manaia, J.; Manaia, A.; Rodriges, L. Industrial Hemp Fibres: An Overview. Fibres 2019, 7, 106. [CrossRef]

17. Trend Economy. Available online: https://trendeconomy.com/data/commodity_h2/530210 (accessed on 13 November 2021).

18. European Commission. Available online: https://ec.europa.eu/info/food-farming-fisheries/plants-and-plant-products/plantproducts/hemp_en, (accessed on 13 November 2021).

19. Zwawi, M. A Review on Natural Fiber Bio-Composites, Surface Modifications and Applications. Molecules 2021, $26,404$. [CrossRef]

20. Pracella, M.; Chionna, D.; Anguillesi, I.; Kulinski, Z.; Piorkowska, E. Functionalization, compatibilization and properties of polypropylene composites with Hemp fibres. Compos Sci Technol. 2006, 66, 2218-2230. [CrossRef]

21. Shahzad, A. A Study in Physical and Mechanical Properties of Hemp Fibres. Adv. Mater. Sci. Eng. 2013, 2013, 325085. [CrossRef]

22. Prasad, L.; Kumain, A.; Patel, R.V.; Yadav, A.; Winczek, J. Physical and Mechanical Behavior of Hemp and Nettle Fiber-Reinforced Polyester Resin-based Hybrid Composites. J. Nat. Fibers. 2020, 1-16. [CrossRef]

23. Oza, S.; Wang, R.; Lu, N. Thermal and mechanical properties of recycled high density polyethylene/hemp fiber composites. Int. J. Appl. Sci. Technol. 2011, 1, 31-36.

24. Lu, N.; Oza, S. A comparative study of the mechanical properties of hemp fiber with virgin and recycled high density polyethylene matrix. Compos. Part B Eng. 2013, 45, 1651-1656. [CrossRef]

25. Lu, N.; Johnson, R.R. Hemp Fibre Reinforced Composite with Recycled High Density Polyethylene and Production Thereof. U.S. Patent 9187624B2, 23 February 2012.

26. Zhijian, L.; Xungai, W.; Lijing, W. Properties of hemp fibre reinforced concrete composites. Compos. A Appl. Sci. Manuf. 2006, 37, 497-505.

27. Cigasova, J.; Stevulova, N.; Sicakova, A. New Biocomposites Based on Hemp Hurds. JCEEA 2015, 62, 75-81. [CrossRef]

28. Tina, H.; Ali, A.; Jalil, M. Hemp fibre reinforced thermoplastic polyurethane composite: An investigation in mechanical properties. Ind. Crop. Prod. 2017, 108, 853-863.

29. Song, Y.S.; Lee, J.T.; Ji, D.S.; Kim, M.W.; Lee, S.H.; Youn, J.R. Viscoelastic and thermal behavior of woven hemp fiber reinforced poly(lactic acid) composites. Compos. Part B Eng. 2012, 43, 856-860. [CrossRef]

30. Ciupan, E.; Lăzărescu, L.; Filip, I.; Ciupan, C.; Câmpean, E.; Cionca, I.; Pop, E. Characterization of a thermoforming composite material made from hemp fibres and polypropylene. In Proceedings of the Modern Technologies in Manufacturing (MTeM 2017-AMaTUC), Cluj-Napoca, Romania, 12-13 October 2017; pp. 537-544. [CrossRef]

31. Etati, A.; Pather, S.; Fang, Z.; Wang, H. The study of fibre/matrix bond strength in short hemp polypropylene composites from dynamic mechanical analysis. Compos. Part B Eng. 2014, 62, 19-28. [CrossRef]

32. Rachini, A.; Mougin, G.; Delalande, S.; Charmeau, J.Y.; Barres, C.; Fleury, E. Hemp fibers / polypropylene composites by reactive compounding: Improvement of physical properties promoted by selective coupling chemistry. Polym. Degrad. Stab. 2012, 97, 1988-1995. [CrossRef]

33. Feng, D.; Caulfield, D.F.; Sanadi, A.R. Effect of Compatibilizer on the Structure-Property Relationships of Kenaf-Fiber/Polypropylene Composites. Polym. Compos. 2001, 22, 506-517. [CrossRef] 
34. Badji, C.; Beigbeder, J.; Garay, H.; Bergeret, A.; Bénézet, J.-C.; Desauziers, V. Natural weathering of hemp fibers reinforced polypropylene biocomposites: Relationships between visual and surface aspects, mechanical properties and microstructure based on statistical approach. Compos. Sci. Technol. 2018, 167, 440-447. [CrossRef]

35. Panthapulakkal, S.; Sain, M. Injection-molded short hemp fiber/glass fiber-reinforced polypropylene hybrid compositesmechanical, water absorption and thermal properties. J. Appl. Polym. Sci. 2007, 103, 2432-2441. [CrossRef]

36. Mutjé, A.; Lòpez, A.M.E.; Vallejos, A.M.E.; López, J.P.; Vilaseca, F. Full exploitation of Cannabis sativa as reinforcement/filler of thermoplastic composite materials. Compos. Part A Appl. Sci. 2007, 38, 369-377. [CrossRef]

37. Ciupan, E.; Ciupan, M.; Jucan, D.-C. Determining the Mechanical Properties of a New Composite Material using Artificial Neural Networks. IJETT 2018, 66, 103-108. [CrossRef]

38. Suardana, N.P.G.; Piao, Y.; Lim, J.K. Mechanical Properties of Hemp Fibres and Hemp/PP Composites: Effects of Chemical Surface Treatment. Mater. Phys. Mech. 2011, 11, 1-8.

39. Zhang, X. Manufacturing of Hemp/PP Composites and Study of its Residual Stress and Aging Behavior. Ph.D. Thesis, Université de Technologie de Troyes, Troyes, France, 2016.

40. Hargitai, H.; Rácz, I.; Anandjiwala, R. Development of Hemp Fibre Reinforced Polypropylene Composite. J. Thermoplast. Compos. Mater. 2008, 21, 165-174. [CrossRef]

41. Souza, B.R.; Di Benedetto, R.M.; Hirayama, D.; de Andrade Raponi, O.; Barbosa, L.C.M.; Ancelotti Junior, A.C. Manufacturing and Characterization of Jute/PP Thermoplastic Commingled Composite. Mater. Res. 2017, 20, 458-465. [CrossRef]

42. Susheel, K.; Kaith, B.S.; Inderjeet, K. Pretreatments of Natural Fibers and their Application as Reinforcing Material in Polymer Composites-A Review. Polym. Eng. Sci. 2009, 49, 1253-1272. [CrossRef]

43. Mehdi, T.; Nazanin, M. Mechanical Performance of Hemp Fibre Polypropylene Composites at Different Operating Temperatures. J. Reinf. Plast. Compos. 2010, 29, 664-667.

44. Thuane, T.S.; Silva, P.H.P.M.D.; Matheus, P.R.; Maurício, F.L.; da Silva, A.P.; Monteiro, S.N.; Cassiano, L.F.N. Thermal and Chemical Characterization of Kenaf Fiber (Hibiscus cannabinus) Reinforced Epoxy Matrix Composites. Polymers 2021, $13,2016$.

45. Jahangir, A.K.; Mubarak, A.K.; Rabiul, I.; Abdul, G. Mechanical, Thermal and Interfacial Properties of Jute Fabric-Reinforced Polypropylene Composites: Effect of Potassium Dichromate. Int. J. Mater. Sci. Appl. 2010, 1, 350-357.

46. Tanvir, S.; Shahin, S.; Husna, P.N.; Wahab, K.M. Impact of Morphological, Physicomechanical of Polypropilene Composites Reinforced with Chemically Modified Betel Nut Husk fiber. IJAR 2019, 7, 1111-1119.

47. Joseph, P.V.; Joseph, K.; Thomas, S.; Pillai, C.K.S.; Prasad, V.S.; Groeninckx, G.; Sarkissova, M. The Thermal and Crystallization Studies of Short Sisal Fiber Reinforced Polypropylene Composite. Mater. Sci. Eng. 2003, 34, 253-266.

48. Ingamells, W. Colour for Textiles: A User's Handbook; Society of Dyers and Colourists: Bradford, UK, 1993; p. 154, ISBN 0901956562/9780901956569.

49. Sergio, N.M.; Calado, V.; Ruben, J.S.R.; Frederico, M.M. Thermogravimetric behavior of natural fibres reinforced polymer composites-An overview. Mater. Sci. Eng. A 2012, 557, 17-28.

50. Anderson, K.S.; Hillmyer, M.A. Melt preparation and nucleation efficiency of polylactide stereocomplex crystallites. Polymer 2006, 47, 2030-2035. [CrossRef]

51. Xu, H.; Liu, C.Y.; Chen, C.; Hsiao, B.S.; Zhong, G.J.; Li, Z.M. Easy alignment and effective nucleation activity of ramie fibers in injection-molded poly(lactic acid) biocomposites. Biopolymers 2012, 97, 825-839. [CrossRef] [PubMed]

52. Zainal, M.; Santiagoo, R.; Ayob, A.; Ghani, A.A.; Mustafa, W.A.; Othman, N.S. Thermal and mechanical properties of chemical modification on sugarcane bagasse mixed with polypropylene and recycle acrylonitrile butadiene rubber composite. J. Thermoplast. Compos. Mater. 2019, 33, 1533-1554. [CrossRef]

53. Franciszczak, P.; Wojnowski, J.; Kalniňš, K.; Piesowicz, E. The influence of matrix crystallinity on the mechanical performance of short-fibre composites-Based on homo-polypropylene and a random polypropylene copolymer reinforced with man-made cellulose and glass fibres. Compos. Part B Eng. 2019, 2019, 516-526. [CrossRef]

54. Prabowo, I.; Pratama, J.N.; Chalid, M. The effect of modified ijuk fibers to crystallinity of polypropylene composite. In Proceedings of the IOP Conference Series: Materials Science and Engineering, Medan, Indonesia, 7-10 November 2016; Volume 223, p. 012020. [CrossRef]

55. Naruedee, P.; Amnouy, L. Wollastonite and talc reinforced polypropylene hybrid composites: Mechanical, morphological and thermal properties. J. Met. Mater. Miner. 2021, 31, 92-99.

56. Noritake, A.; Mitsuo, H.; Mikiji, S.; Mitsuhiko, T. Recycling of Polyethylene Terephthalate Using High-pressure Steam Treatment. J. Polym. 2008, 40, 498-502. [CrossRef]

57. Alessandro, P.; Amabile, P. Recycled poly(ethylene terephthalate) and its short glass fibres composites: Effects of hygrothermal aging on the thermo-mechanical behaviour. Polymer 2004, 45, 7995-8004.

58. Alves, N.M.; Mano, J.F.; Balaguer, E.; Meseguer, J.M.D.; Gómez Ribelles, J.L. Glass transition and structural relaxation in semi-crystalline poly(ethylene terephthalate): A DSC study. Polymer 2002, 43, 4111-4122. [CrossRef]

59. Huang, J.M.; Chu, P.P.; Chang, F.C. Conformational changes and molecular motion of poly(ethylene terephthalate) annealed above glass transition temperature. Polymer 2000, 41, 1741-1748. [CrossRef]

60. Jung, M.R.; Horgen, F.D.; Orski, S.V.; Rodriguez, C.V.; Beers, K.L.; Balazs, G.H.; Jones, T.T.; Work, T.M.; Brignac, K.C.; Royer, S.J. Validation of ATR FT-IR to identify polymers of plastic marine debris, including those ingested by marine organisms. Mar. Pollut. Bull. 2018, 127, 704-716. [CrossRef] 
61. Mofokeng, J.P.; Luyt, A.S.; Tábi, T.; Kovács, J. Comparison of injection moulded, natural fibre-reinforced composites with PP and PLA as matrices. J. Thermoplast. Compos. Mat. 2011, 25, 927-948. [CrossRef]

62. Luisa, A.; Ioana, D.P.; Rodica, S.; Zorita, D.; Alina, T.; Cristina, H.; Ancuta, R. Characterization of Flax and Hemp Using Spectrometric Methods. Appl. Sci. 2021, 11, 8341. [CrossRef]

63. Célino, A.; Gonçalves, O.; Jacquemin, F.; Fréour, S. Qualitative and quantitative assessment of water sorption in natural fibres using ATR-FTIR spectroscopy. Carbohydr. Polym. 2014, 101, 163-170. [CrossRef]

64. Shi, J.; Xing, D.; Lia, J. FTIR Studies of the Changes in Wood Chemistry from Wood Forming Tissue under Inclined Treatment. Energy Procedia 2012, 16, 758-762. [CrossRef]

65. Javier-Astete, R.; Jimenez-Davalos, J.; Zolla, G. Determination of hemicellulose, cellulose, holocellulose and lignin content using FTIR in Calycophyllum spruceanum (Benth.) K. Schum. and Guazuma crinita Lam. PLoS ONE 2021, 16, e0256559. [CrossRef]

66. Ruth, C.; Asensio, M.S.A.M.; José, M.R.; Marisa, G. Analytical characterization of polymers used in conservation and restoration by ATR-FTIR spectroscopy. Anal. Bioanal. Chem. 2009, 395, 2081-2096. [CrossRef] 